\title{
Melilla \& las plazas menores (Chafarinas; Velez de la Gomera; Alhucemas) en el «Diccionario Geográ- fico-Estadístico-Histórico de España y sus posesiones de ultramar» (Madrid, 1845- 1850) de Pascual Madoz
}

Edición, Introducción y Notas

Vicente Moga Romero

I. Introducción.

II. Notas estadísticas e históricas escritas por D. Pascual Madoz para el Atlas de D. Francisco Coello (Madrid, 1850).

III. "Plaza de Melilla", plano de Francisco Coello (Madrid 1850).

IV. Transcripciones de las voces del diccionario:

- Melilla

- Chafarinas

- Vélez de la Gomera

- Alhucemas

V. Notas.

\section{I.- Introducción}

\section{Justificación}

La publicación de una obra de la envergadura del Diccionario de Madoz, contribuyó en su momento, y contribuye ahora, al mejor conocimiento de la historia del siglo XIX espafiol. De ahi que las ediciones parciales de las distintas voces del Diccionario, por las diferentes provincias y comunidades españolas, no se haya hecho 
esperar. En efecto, en el marco de la asunción por parte de las diversas Comunidades Autónomas Españolas de sus propias coordenadas culturales, se ha posibilitado la valoración de una literatura reforzadora de sus propios hechos diferenciales. Así, no nos puede resultar extraño que la publicación de temas locales sea patrocinada por las instituciones oficiales y arropadas por múltiples colectivos de la Comunidad, incluídas las entidades privadas.

No necesita justificación, aunque la estemos haciendo, pues, la edición de la parte del Diccionario de Madoz que se refiere a "Melilla" y, también, a otros enclaves como "Peñón de Vélez de la Gomera", "Islas Chafarinas" y "Alhucemas". Posiblemente sea Melilla la única ciudad espafiola que aún no tenía una edición propia del libro de Pascual Madoz.

Nos parece pues justificado y, además, pensamos que esta edición se plantea como la satisfacción de una demanda cultural urgente, que no debe quedar aislada, sino que tiene que intentar estimular planteamientos estructurales que permitan construir una original y peculiar historia y asumir nuestras propias connotaciones culturales.

\section{Agradecimientos}

No sería correcto dejar pasar la ocasión de manifestar nucstro agradecimiento a todos aquellos que han mostrado su apoyo al proyecto y así lo han hecho posible. En primer lugar a la propia UNED-Melilla. También a la Asociación de Estudios Mclillenses, ya que mucho de lo vertido aquí es consecuencia de coloquios organizados por ella. Y, por último, a la Biblioteca Pública Municipal de Mclilla, que ha facilitado la reproducción del Diccionario que conserva. A título personal, es también de justicia agradecer a Alí Mohamed y Santiago Domínguez Llosá la ayuda e información facilitadas, así como a Jesús Sáez Cazorla, Antonio Bravo Nicto, Francisco Saro Gandarillas y Claudio Barrio Fernández de Luco, sin los cuales obras como esta no serían posibles.

\section{Nuestra edición}

Madoz titula su obra Diccionario geográfico-estadístico-histórico de España y sus posesiones de Ultramar y explica en el "Prólogo" (1845, Tomo I, p. IX) que "cse título que pudiera parecer vano y pomposo, corresponde sin embargo fielmente a la intención, a la idea que tengo formada de mi libro, cuyo objeto principal debe ser, según yo entiendo, el dar a conocer con la extensión posible lo que es, lo que en su día podrá ser, y lo que fue en otro tiempo el país que se describe, cosa que no puede conseguirse sino por medio de la geografia, de la estadística y de la historia". Recogiendo esta declaración de intenciones y pensando que es de gran interés su publicación, presentamos las voces del Diccionario referentes a "Melilla", "Peñón de Vélez de la Gomera", "Islas Chafarinas" y "Alhucemas". ${ }^{1}$ Tan sólo no hemos recogido "Ceuta" de entre los enclaves españolas en Marruecos, porque su propia envergadura requiere un estudio aparte. ${ }^{2}$

Hemos impreso exactamente, y de forma completa, lo que escribiera Madoz. Tan sólo hemos desarrollado abreviaturas y, en pocos casos, hemos cambiado alguna palabra para la mejor adecuación de la frase al contexto actual. 
La edición se complementa con el Mapa de Melilla, obra de Francisco Cocllo, que ilustra las explicaciones y que ha sido delineado por $\mathrm{R}$. Bayón.

Las notas introducidas en el texto son nuestras e intentan aclarar algunos aspectos que pudieran resultar desconocidos. Con ello queremos contribuir a la mayor divulgación del contenido.

En cuanto a la edición clegida, ha sido la primera edición, publicada en 16 volúmenes, en Madrid, entre 1845 y 1850 . A cada una de las voces que anotamos a continuación les corresponden los siguientes epígrafes, años de publicación, tomos y páginas:

*"Melilla" (1848), Tomo XI, p. 361-363;

*"Islas Chafarinas" (1848), Tomo XI, p. 363;

*"Peñón de Vélez de la Gomera" (1849), Tomo XV, p. 640-642;

*"Alhucemas" (1845), Tomo II, p. 213-214.

\section{Los Autores}

Pascual Madoz (Pamplona 1806 - Génova 1870) se constituyó en su época en uno de los introductores de la ciencia estadística en España. Ausente nuestro país de publicaciones al estilo de las realizadas en Francia e Inglaterra, Madoz realiza la traducción de la Estadística de España de Moreau de Jonnès (1835) y la aplica, en la medida de lo posible, dada la poca fiabilidad de los datos - matrículas catastrales por ejemplo- a la confección de su monumental y espléndido Diccionario.

Entre 1845 y 1850 aparecen en Madrid los 16 volúmenes del Diccionario Geográfico-Estadístico-Histórico de España y sus posesiones de ultramar. La obra está dedicada, por su autor, a "mi reina", Isabel II, apenas declarada mayor de edad en 1843, en el inicio de lo que vino en denominarse la década moderada. Reina de España desde 1833, la "Plaza de Melilla" contribuyó a homenajearla dando el nombre de la "Plaza Real de Isabel II, heredera de Fernando VII", a la denominada hasta entonces de Fernando VII, el 27 de abril de 1834, seis meses después de su proclamación como reina el 24 de octubre. ${ }^{3}$

El Diccionario nace, como confiesa Madoz, en época de agitaciones, "circunstancias independientes de mi voluntad". España profundizaba en sus propias heridas internas y acufaaba una palabra española universalmente conocida: el pronunciamiento. Desde el inicio de las guerras carlistas (1833), ${ }^{4}$ hasta el advenimiento de la "gloriosa" revolución (1868), el período isabelino fue rico en turbulencias. Durante su reinado tuvo también lugar la guerra de Africa (1859-1860) que propiciaría el nacimiento de una nueva etapa para la historia de "Melilla". Madoz compaginó su vocación científica con el desempeño de la abogacía y la política. Dentro del liberalismo progresista, Madoz pasará a la historia por su proyecto de ley de desamortización civil y eclesiástica, durante su gestión como ministro de Hacienda, en el primer semestre de $1855 .^{5}$ Por azar, la edición ut supra citada del Diccionario posiblemente provenga de los efectos de la desamortización ya que procede del Monasterio de Poyo, en Pontevedra, como expresa su ex-libris.

Pascual Madoz, moriría en Génova, cuando formaba parte de la comitiva destinada a ofrecer la corona vacante de España al duque de Aosta, Amadeo de Saboya, en 1870. 
Francisco Coello (Jaén 1822 - Madrid 1898) publicó como complemento a la obra de Madoz, el Allas de España y posesiones de ultramar, al que pertenece el Mapa de Melilla que reproducimos (1850) y cuyo original se nos ha facilitado amablemente por el Museo Municipal de Melilla.

Militar y geógrafo, aunó las dos profesiones, y se convirtió en un adelantado de la geografía como ciencia en España. Tuvo además facilidades que aprovechó ya que su paso por la Dirección General de Ingenieros, y el libre acceso a los archivos de los distintos ministerios, le facilitó la confección del Atlas. Por otra parte, hizo acopio de su experiencia de campo, ya que participó como agregado militar del ejército francés, en operaciones en Argelia. Ello quedó plasmado en una Memoria sobre las operaciones del ejército francés (1846).

Su colaboración activa en el nacimiento y desarrollo de sociedades especializadas, como la Sociedad Geográfica de Madrid (1876) y otras, incidieron en su importancia como impulsor de la geografía cientíica. ${ }^{6}$

Las hojas del Atlas llevan unas Notas escritas por el propio Madoz que sirven de explicación a los mapas y que complementan, en todo caso, las voces de su Diccionario. De ahí la conveniencia de su exposición en las líneas que siguen.

\section{II.- Notas Estadísticas e Históricas escritas por D. Pascual Madoz para el atlas de D. Francisco Coello (Madrid, 1850)}

Estas Notas de Madoz expresan la decadencia alcanzada por España en sus posesiones norteafricanas. Hay, pućs, una queja explícita de la debilidad del poderio español en Africa:

"Sólo cinco puntos tiene la España ocupados en la costa septentrional de Africa. Este es el resto de las numerosas y brillantes conquistas que se hicieron por nuestras armas después de la expulsión de los moros de la Península, y que dieron por resultado la ocupación de todas las fortalezas y puertos importantes situados en el largo espacio de 800 leguas de costa, que median desde el Cabo Nun, enfrente de las Islas Canarias, hasta los límites occidentales de Egipto. Grandes porciones del interior reconocían entonces la soberanía de nuestra nación y le pagaban sus tributos, y todavía quedan magníficos restos y grandes recuerdos de nuestra dominación en Túnez, Bugía, Argel, Orán y otros puntos, a cuyo lado aparece todavía mezquina la pequeñez de nuestros actuales establecimientos. ${ }^{\text {? }}$

Además, Madoz hereda el abandonismo borbónico (Felipe V, Fernando VI, Carlos III) personificado en Aranda, ${ }^{8}$ y que a su juicio no reporta beneficio alguno a España:

"Si se exceptúa Ceuta, plaza notable por sus grandiosas fortificaciones y por su interesante posición en el estrecho de Gibraltar, bien puede decirse que nuestra ocupación en Africa no nos reporta ventaja alguna y es por el contrario onerosa para nuestro erario y aún poco gloriosa para nuestras armas. Encerradas en sus pequeños islotes o peñascos las guarniciones de Vélez de la Gomera y Alhucemas y en su corto recinto la de Melilla; sitiadas y molestadas continuamente por los bárbaros y miserables habitantes de las tribus y pueblecillos inmediatos, ven perecer a menudo algunos de sus soldados, sin utilidad alguna para el prestigio de nuestro nombre sin servir para proteger o fomentar el comercio, ni para ganarse las simpatías de los naturales que 
por el contrario se alejan más de día en día. Más bien que como dominadores o conquistadores, aparecemos allí como sujetos y encarcelados por los enemigos, viéndonos en la triste necesidad de conducir todos los víveres y hasta el agua muchas veces de nuestro territorio. Los pequeños y no muy seguros fondeaderos para buques de cscaso porte, que tienen a su inmediación estos tres puntos, si están protegidos por nuestros fuegos, están también expuestos a los del enemigo, los buques de alto bordo sólo pueden fondear fuera del tiro de cañón en la espaciosa, pero insegura, bahía de Alhucemas y en la rada de Melilla, que no ofrece tampoco casi ningún resguardo. Si en un tiempo la ocupación de estos puntos pudo ser conveniente para extinguir la piratería, hoy la juzgamos innecesaria bajo todos conceptos y más útil sería ocupar un sólo puerto de la costa occidental de Marruecos, que podría ser muy interesante, ya en el presente para las negociaciones a Canarias, ya en el porvenir para toda invasión en el tcrritorio del imperio. Para esta empresa, en la cual parece que tarde o temprano habrán de emplearse nuestras armas forzadas o por circunstancias políticas o por el exceso de población de nuestra península que en ningún punto podrá desbordar más ventajosamente que en este territorio, que es casi la continuación de nuestro país, tampoco presentaría ninguna ventaja la conservación de estas tres fortalezas. Su situación enfrente de altas y escabrosas montaña hace que sólo puedan servir para la dominación de pequeños valles en cuya desembocadura se encuentran, los cuales no tienen comunicaciones fáciles con el interior. Inútil sería por lo tanto tratar de remediar la poca capacidad o la inseguridad actual de sus defensas estableciendo en tierra firme nuevas líneas de fortificaciones; lo que ahora sucede con los primeros recintos sucedería después con los más avanzados que sólo acarrearian gastos y aumento de guarnición".

Para Madoz, como vemos, sería más práctico y útil ocupar un sólo puerto en la costa occidental de Marruecos, 0 , incluso, centrarse en las Islas Chafarinas y acondicionar su puerto:

"Bajo todos estos puntos de vista la ocupación de las Chafarinas es incomparablemente más acertada. Entre las tres islas existe un buen fondeadero natural que puede mejorarse con el arte. Su proximidad a la costa, desde la cual sin embargo no pueden ser molestados sus defensores, y la circunstancia de hallarse situadas enfrente del Río Muluya, separación de la Argelia y de Marruecos, el cual se extiende hacia el corazón de este imperio indicando la única línea de invasión marcada por la naturaleza en toda la costa al Este del estrecho de Gibraltar les dan una grande importancia. El día en que las Chafarinas se hallen fortificadas de una manera estable, para lo cual tanto se presta su topografía presentarán un punto de sumo interés y el único digno de ccuparse al Oriente de Ceuta de los que actualemtne poseemos".

En definitiva, Madoz demuestra un excelente conocimiento de la situación de los enclaves españoles en Africa, haciendo gala a las fuentes históricas por él utilizadas. En su mismo Diccionario cita el Catálogo de las obras consultadas para la redacción de este Diccionario, que sirve de colofón a su Introducción general (1845, Tomo I). En este catálogo aparecen las obras manejadas por Madoz y que incluyen algunas tan importantes para Melilla como la del historiador melillense Juan Antonio de Estrada, Población General de España e islas adyacentes (Madrid, 1748), obra cuyo enciclopedismo guarda cierta semejanza con la de Pascual Madoz. ${ }^{10}$ 


\section{Notas de Pascual Madoz al plano que reproducimos de Francisco Coello.}

Peñón de Vélez de la Gomera: Su guarnición habitual es de 300 hombres escasos: tiene ordinariamente 400 presidarios aun cuando su numero no debe pasar de 250 . Estos y las familias de algunos empleados forman toda la población. El costo de esta plaza es de $750.000 \mathrm{r}^{5}$. anuales sin contar el de la guarnición y gefes que le hacen subir a 1.500.000. Ocupó esta fortaleza Pedro Navarro en 23 de julio de 1508: se perdió en 1522 y se volvió a ocupar en 1564: desde esta fecha ha continuado en nuestro poder apesar de haber sido situiada diferentes veces.

Peñón de Alhucema: La guarnición de esta fortalcza es de 120 hombres que cuidan de 70 a 100 confinados. No hay más población que está y algunos empleados con sus familias. Su costo es de $1.000 .000 \mathrm{de} \mathrm{r.} .^{5}$ al año. Fue tomada en 28 de agosto de 1673 por los naves Españolas San Agustín y San Carlos cuyos nombres llena también este presidio.

Melilla: Ciudad con fortificaciones respetables su guarnición es de 1.000 infantes y algunos caballos a las órdenes de un general gobernador: la población la componen además de esta alguna brigada de presidarios y unas 150 familias. El costa anual de esta plaxa sin centrar el de su guarnición es de $1.500 .000 r^{s}$ anuales proximamente. Desde 1496 en que fue ocupada por nuestras armas ha sufrido diferentes ataques pero sin dejar de contarse en el numero de nuestras posesiones.

Islas Chafarinas: Han sido ocupadas en 6 de enero de 1848 y desde entonces se trabaja en las fortificaciones y edificios para su guarnicion: la isl central llamada de Isabel $2^{a}$ es la que se trata de defender principalmente.

Adempás de los cinco puntos descritos pertenecen a la España de la Isla del Peregil, la de Albarán y la de Limacos o Caracoles que no están ocupadas la $3^{3}$ esta en territorio de la Argelia. 


\section{III. "PLAZA DE MELILLA" PLANO DE FRANCISCO COELLO MADRID, 1850}

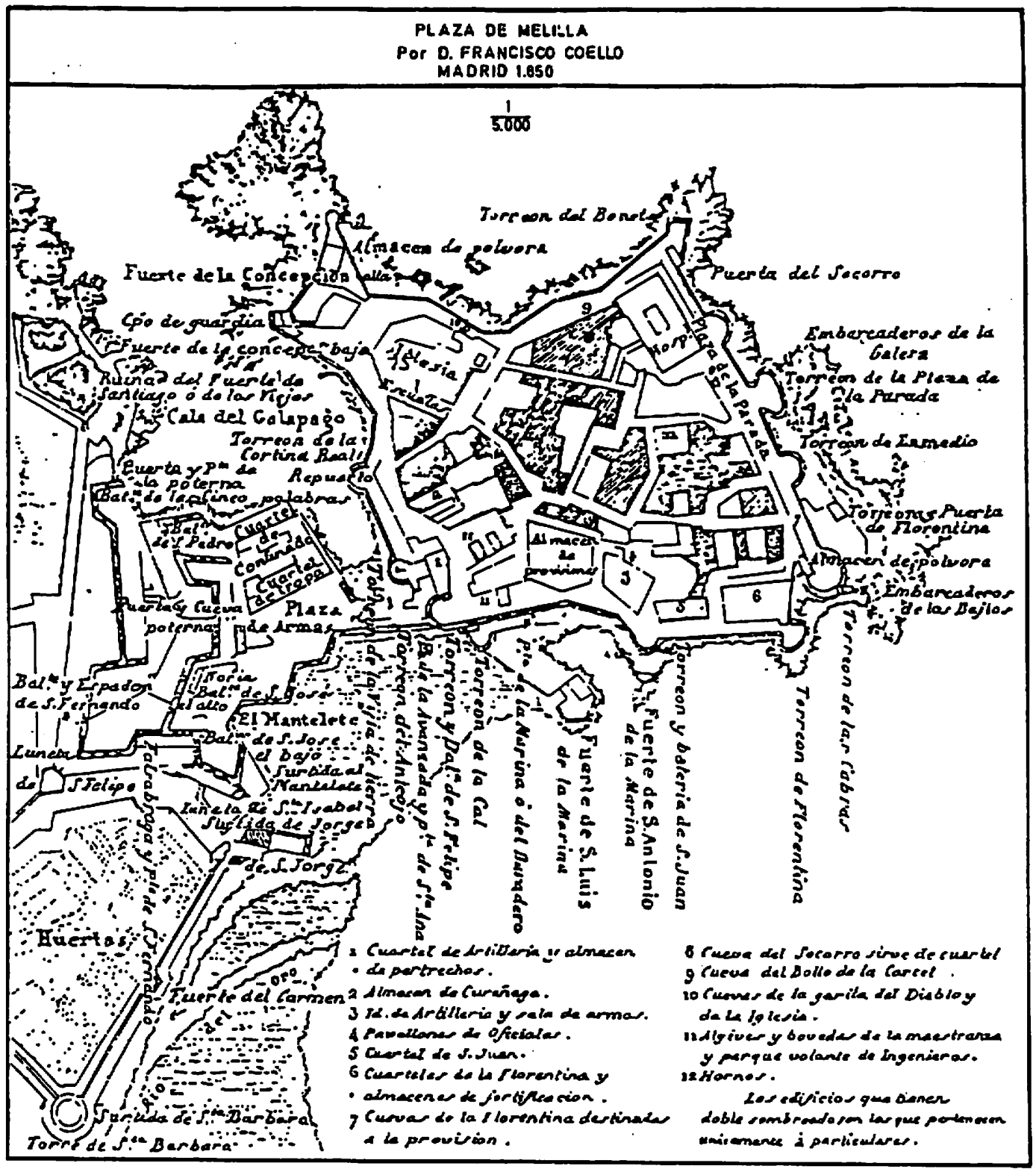


IV. TRANSCRIPCIONES DE LAS VOCES DEL "DICCIONARIO"

-MELILLA

-ISLAS CHAFARINAS

-PENON DE VELEZ DE LA GOMERA

-ALHUCEMAS 


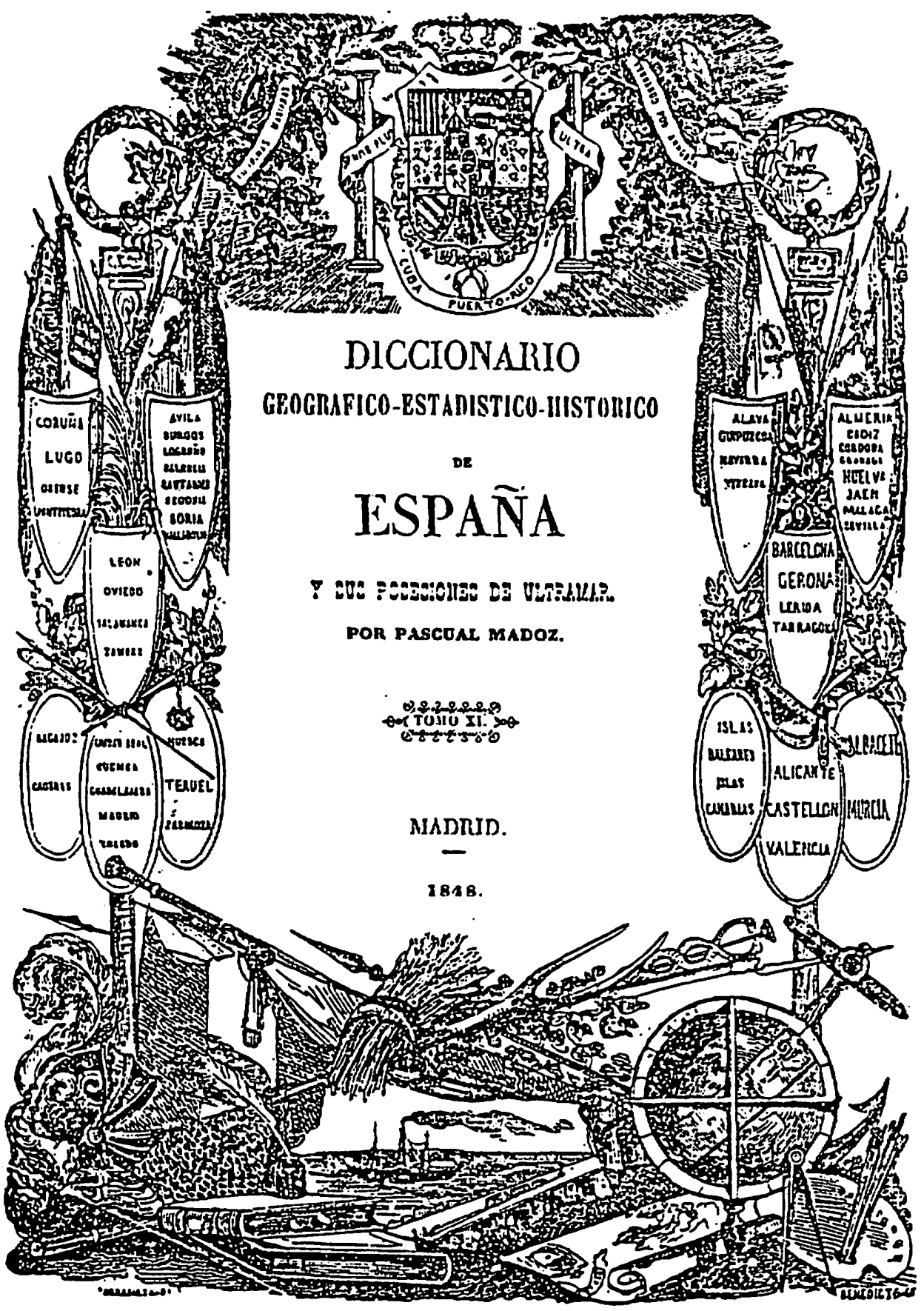

Imprenta del Diccionario Geográfico, a cargo de D. José Rojas. Calle de la Madera Baja, número, 8.

Madrid, 1848, Tomo XI. 


\section{Melilla}

Melilla. Ciudad de Africa en el Imperio de Marruecos; " plaza fucrte y presidio menor dependiente del mayor de Ccuta a cuya capitanía general nuevamente creada pertenece hoy, agregada al partido judicial de Algeciras, provincia de Cádiz. ${ }^{12}$

Se halla SITUADA ${ }^{13}$ en el Mediterráneo en la costa de la provincia de Garett por latitud de $35^{\circ} 20^{\prime} 50^{\prime \prime}$ y longitud $3^{\circ} 22^{\prime} 35^{\prime \prime} 45^{\prime \prime}$, al sur, $17^{\circ}$ Este del cabo Tres Forcas distancia de 8 millas, 38 leguas al Sudeste de la costa de Motril, 50 al Oeste de Orán, 50 al Este de Ceuta, 25 del Peñón, 18 de Alhucemas y 58 al Suroeste de Marruecos. ${ }^{14}$

La plaza ocupa una península unida al continente por un istmo de roca de 121 varas de longitud, 95 de latitud y 35 de elevación sobre el nivel del mar. Tiene como unas 800 varas de travesía desde la muralla real hasta la última línea avanzada de que puede disponer la plaza, habiendo entre sus fortificaciones exteriores, unos huertos que producen abundantes hortalizas. ${ }^{15}$ El frente Norte de la plaza es inaccesible por lo escarpado y clevado de la peña; el frente Este que mira al mar tiene un antepecho y en su mitad un torreón o barbeta de figura elíptica, y el ángulo Sur otro cilíndrico llamado de las Cabras. En el frente Oeste está la puerta de la plaza y el torreón de Santiago con las correspondientes minas de comunicación a los fuertes exteriores.

Cinco partidos o Alcalahias rodean a Melilla, que son Mazuce, Benciferor, Beneusidel, Benézicar y Bene-gullafar, a los cuales está encomendada la guardia del campo que cubten cada tres días unos 200 hombres armados, bajo las órdenes de un moro principal que llaman cabo. ${ }^{16}$ Cercan la plaza a tiro de cañón las alturas de San Lorenzo, Santiago, San Francisco y el cerro de la Horca, sobre los cuales hubo en otro tiempo fortificaciones españolas a distancia de medio tiro de fusil de los fuertes de Rosario, Victoria Grande y Chica. ${ }^{17}$

En la continuación de la costa de Africa como ya hemos expuesto, existe Melilla, ocupando el que llaman su primer recinto la irregularidad de una roca con diferentes alturas y separada del mar por un foso de 100 varas de largo y abierto artificialmente. Se extiende su segundo, tercer recinto y obras extcriores con el continente, componiéndose de los torreones antiguos y algunos pedazos con baterías y baluartes de nueva planta en la forma siguente:

Primer recinto. En este recinto están como obras de defensa y fortificación el torreón de Anteojo, el de la Muralla Real, Batería de la Concepción, la llamada Alta, el Bonete, Torreón de Cabras, el de la Florentina, el de San Juan, el de la Avanzada, el de la Cal y la batería sobre la Maestranza. En la marina perteneciente a este recinto se hallan el fortín de San Antonio y la batería de San Luis, las puertas de la Avanzada, la de la Marina, la de la Florentina y la del Socorro.

Segundo recinto. Hay en él la batería de la plaza de Armas, los baluartes de San José (Bajo y Alto), baluarte de San Pedro con flanco bajo, el cuartel de tropa y presidiarios, el cuerpo de guardia y la plaza y puerta de Armas.

El tercer recinto está compuesto del baluarte de San Fernando y el de las Cinco Palabras. Las obras exteriores las forman la luneta de San Felipe y Santa Isabel, el fortín del Espigón y el del Carmen, la torre de Santa Bárbara, el reducto de San Miguel y el 
de San Carlos, los fuertes de la Victoria Chica y Grande, el del Rosario, la luneta de San Antonio la batería que defiende el foso de San Miguel y el rastrillo de Espadas. ${ }^{18}$ La mayor parte del recinto extcrior está dominado a tiro de fusil por las alturas del Ataque Seco y del Tarara, y viene apoyándose por su flanco derecho en una cortadura que baja hasta el mar, la cual como las demás obras están coronadas por la artillería que manifiesta el siguiente estado. ${ }^{19}$

\section{Cañones de Bronce}

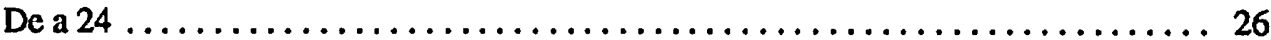

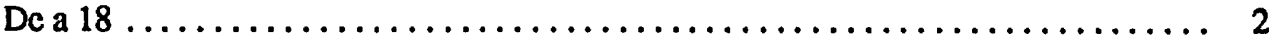

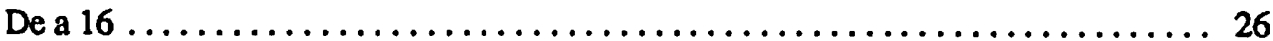

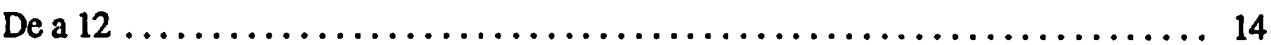

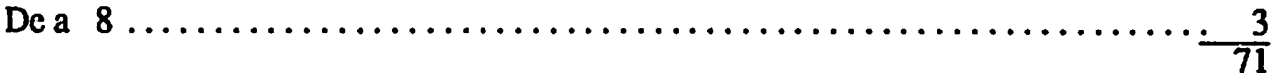

Cañones de Hierro

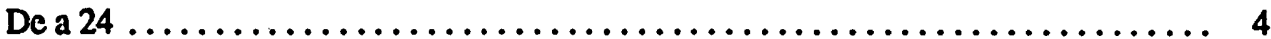

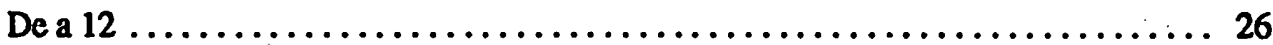

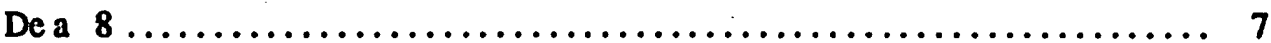

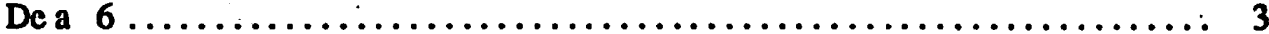

De a $2 \ldots \ldots \ldots \ldots \ldots \ldots \ldots \ldots \ldots \ldots \ldots \ldots \ldots \ldots, \ldots \ldots \ldots, \frac{2}{42}$

Culcbrinas de bronce

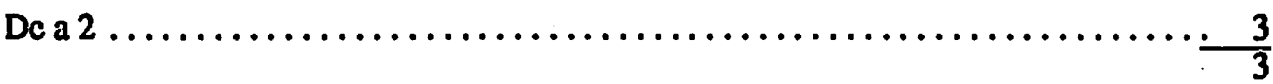

\section{Morteros}

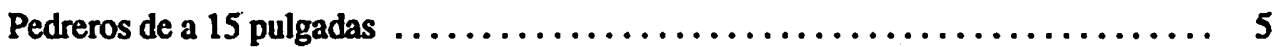

Pedreros de a 14 pulgadas $\ldots \ldots \ldots \ldots \ldots \ldots \ldots \ldots \ldots \ldots \ldots \ldots \ldots \ldots \ldots, 1$

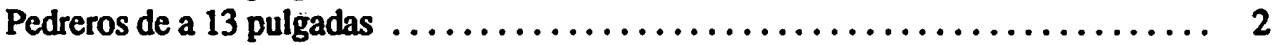

Pedreros de a 12 pulgadas $\ldots \ldots \ldots \ldots \ldots \ldots \ldots \ldots \ldots \ldots \ldots \ldots \ldots \ldots, 7$

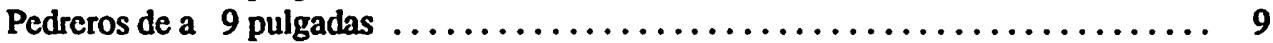

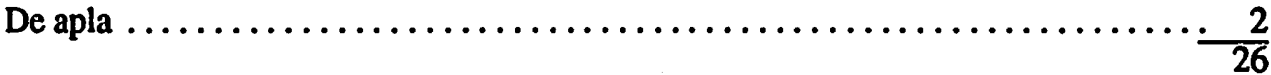

Obuses

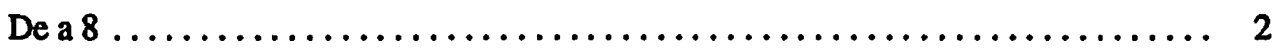

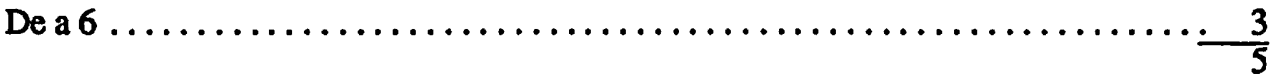


Las calles de la ciudad son desiguales $\mathrm{e}$ incómodas pero muy limpias. Sus casas cstán bastante deterioradas y nuevamente se han destruido muchas, a consecuencia del espantoso terremoto que en la noche del 11 de febrero de este año (1848), se sintió acompañado de un terrible huracán, el cual echó a tierra muchos edificios y parte de la muralla, haciendo dos grandes aberturas en la iglesia parroquial. ${ }^{20}$ Hay sin embargo algunos edificios que se conservan en buen estado, entre los cuales se distinguen la iglesia, el pabellón del clero castrense, la botica real, el parque y maestranza de ingenieros, los cuarteles de la compañía de preferencia, la torre del vigía con su reloj, la casa del comandante de ingenicros y el Hospital Real. Abunda esta plaza de agua potable con la que se riegan las huertas anteriormente nombradas, teniendo además dos magníficos aljibes que recogen toda el agua llovediza de la plaza, el uno capaz de contener 30.000 quintales y 6 libras de agua, y el otro 4.993 quintales y 92 libras. Hay un hospital para 60 camas con todas las oficinas correspondientes. Una iglesia parroquial con la advocación de Nuestra Señora de la Concepción. Los almacenes son espaciosos, todos a prueba de bomba y capaces de contener municiones y viveres para 10.000 hombres durante un año de sitio. Conticne este presidio 97 casas y 24 cuevas, de las que 23 de éstas y 11 de aquellas son de la nación, habitadas algunas de balde. Debajo de las casas y alrededor de la muralla de mar, hay cuevas y habitaciones subterráneas para colocar las oficinas y hospitales en caso de guerra. ${ }^{21}$

Dos muelles o desembarcaderos sirven de entrada a la plaza. El que llaman de la Marina defendido por los fuertes de San Luis y de San Antonio, bajo la protección de la batería de San Felipe y el del Torreón de San Juan; Este muelle comunica con la ciudad por un puente levadiso que da paso a la poterna del principal. El otro muelle se titula de Florentina, el cual está defendido por el Torreón de las Cabras, la batería de Enmedio, la de la Parada y el baluarte del Bonete, puntos de la muralla del mar, que se prolonga por aquel lado hasta el baluarte de la Concepción. Una gran noria abierta en la plaza de armas surte de agua los cuarteles inmediatos y en la mina de comunicación con el fuerte de San Miguel, brota una fuente, cuyo líquido es muy exquisito. Las explanadas son espaciosas; en ellas está el cementerio y en otro tiempo se veían allí hermosos jardines y un hospital, del que sólo se conservan las ruínas. ${ }^{22}$

La vega de Melilla no es grande, pero pudiera ser deliciosa si los moros la cultivasen. Báñala un río de mediano caudal llamado del Oro que desemboca en el día muy cerca de las fortificaciones inferiores de la plaza. Las arenas que arrastra este río han dilatado sobremanera la playa española del Mantelete, en la cual pudieran formarse huertas, casas, almacenes, cuarteles y otros edificios, pero en el día sólo sirve de mercado, cuando concurren los moros con algunos efectos y para recibir con aparato militar las visitas que en varias épocas suelen hacer al gobernador de la plaza algunos magnates marroquies. ${ }^{23}$

Los artículos que en estos mercados se expenden importados por los marroquíes, son los que a continuación fijamos.

Tarifa de los precios que tienen varios efectos de los moros en la plaza de Melilla 


\section{EFECTOS}

La fanega de trigo superior de 8 arrobas y media cada una La fanega de cebada colmada y apretada, que son de 2 españolas

La fanega de habas, 2 españolas

Aceite la arroba española

Almendrás la arroba española

Dátiles la arroba española

Las vacas las venden al contratista a precios convencionales pero la libra duple se vende en la plaza lo más a 9 cuartos

Los carneros vivos mayor y menor

Las gallinas grandes y chicas

El ciento de huevos

El ciento de naranjas

El ciento de cebollas riquísimas

El ciento de nueces

Pasas, libra española 4 cuartos, uvas, peras y brevas a 2 cuartos, higos chumbos, espárragos y caracoles en cambio de anzuelos, cascabeles, tijeras y jabón ...........

Jaiques de seda riquísimos

Jaiques de algodón y estambre finos ................

Jaiques de estambre sólo, finos

Jaiques de estambre ordinarios

Fajas de seda

Fajas de algodón y seda rayadas

Fajas de lana ordinarias

Estambre (la libra)

Pieles encarnadas

Pieles amarillas

Babuchas bordadas

Babuchas sin bordar

Frasquitos de esencia de la Arabia

Lana lavada

Jabalíes pequefios

Un puerco espín

Una olla grande de miel
Precios Reales de vellón

de 55 a 70

de 24 a 40

a 80

a 60

a 50

a 50

de 25 a 35

a 3

a 10

a 8

a 10

a 2

a 150

a 80

de 50 a 70

de 30 a 40

a 20

a 24

a 14

a 8

a 12

a 10

de 12 a 16

de 6 a 8

de 6 a 8

a 60

de 12 a 20

de 12 a 20

de 4 a 12

NOTA. Siendo muy pocos los moros que se dedican a este tráfico por estar prohibido, así por nuestro Gobierno como por el de Marruecos, los precios se resienten de la falta de concurrencia, y aunque ínfimos, son triple de lo que pudiera ser dándoles franca entrada en el mercado de la plaza. En los alrededores de Melilla cuesta una vaca 50 reales, un carnero 8, una cabra 5 y una carga grande de leña 4 cuartos. También sucede que en cambio de estos efectos toman los moros brea, alquitrán, vinagre, pañuelos ordinarios, quincalla, arcas y puertas de pino, espejos, cerraduras y otras 
frioleras. Muchas veces cambian sus frutas, gallinas, miel y huevos por la compostura de sus calderos en la plaza. A estos artículos están reducidos los recursos de los habitantes de la plaza, teniendo los moros de las ciudades y pueblos inmediatos que ir a buscar a Mogador el café, la azúcar, el papel, lomo y otros efectos de que se podrían proveer por Melilla y Ceuta con lo cual ganaría mucho esta plaza. ${ }^{24}$

Dada una idea sucinta de la plaza de Melilla, sus fuertes y demás circunstancias que en ella concurren, lo haremos ahora de sus fondeaderos, cuyo surgidero está al Sur de la plaza y sólo puede servir para buques pequeños por 13 y 13 y medio piés de agua arena a 80 varas de la ribera. Las embarcaciones grandes fondean en la rada a la distancia de $1 / 2$ leguas a 1 al Este por 20 a 27 brazas arena y cascajo colorado, siempre prontos para dar la vela al primer indicio del viento Este, con el que las corrientes que siguen sus tendencias por la costa, rechazadas por el frontón de la tierra que corre al cabo de Tresforcas, suelen sacar a barlovento a los que forcejean por montarlo. Al Norte y Oeste de la plaza había un pequeño puerto o abrigo que ya no existe por haber ganado la playa al Norte hasta alinearse con la plaza. Esta rada está descubierta a los vientos del primero y segundo cuadrantes, siendo su travesía al Este, que es el que más reina. Los vientos del Oeste soplan casi siempre con furor por venir oprimidos entre las montañas y aunque no levantan mar, se necesitan buenos cables para mantenerse. Desde el ángulo Sudeste de la muralla de la plaza de Melilla demora lo más Sudeste del monte Caramú o Gurugú al Sur $00^{\circ} 30^{\prime}$ Oeste, lo más Noroeste al Sur $68^{\circ}$ Oeste y su medianía al Sur $28^{\circ}$ Oeste distancia 1 legua. Al Oeste Sudoeste de la plaza, distante como 1 milla, se halla la boca ciega del río de Oro, y en su orilla del Sur un montecito o promontorio de piedra al que llaman Ataque del Río, en el que tienen los moros un parapeto, de donde hacen fuego a las embarcaciones menores cuando bajan a la plaza. Desde este punto sigue la ensenada con playa al Sur $50^{\circ}$ Este $71 / 2$ millas hasta la punta de la restinga. A $1 / 2$ legua Sudeste de dicha punta se halla la boca de la laguna llamada de Puerto Nuevo, en otro tiempo navegable para pequeñas embarcaciones destinadas a la pesca del coral y nácar, pcro un terremoto en 1755 la cerro, estando obstruída en la actualidad. ${ }^{25}$

La plaza de Melilla presenta en el día, comparada con su antiguo esplendor un aspecto pobre y abatido. En tiempo de D. Fernando VI dominaban el país inmediato a la plaza los espanoles, y los moros contenidos a gran distancia de nuestras fortificaciones, reconocían y acataban la autoridad de nuestros gobernadores, conservando con ellos relaciones amistosas. ${ }^{26} \mathrm{La}$ inmediata vega era entonces un jardín delicioso que cultivaban pacíficamente los habitantes, extendiendo sus labores hasta más allá de las alturas de Fraxama, ${ }^{27}$ y sus ganados pacían a 1 legua de los fuertes exteriores. Había siempre en Melilla un guarnición numerosa, y además existían varias compañías fijas de voluntarios hijos del país, que por sus hechos de armas se habían granjeado el aprecio del Gobierno y el respeto de los moros. Más poco a poco fue decayendo de un estado tan floreciente, después de la muerte del gobernador D. Antonio de Villalba y Angulo, a cuyo interés y desvelos se debía en gran parte la prosperidad de esta colonia. ${ }^{28}$ Las medidas desacertadas que sería prolijo enumerar, puestas en ejecución por el Gobiemo, y la poca inteligencia de algunos Gobernadores, ${ }^{29}$ contribuyeron a 
precipitar la decadencia de un punto, que hoy se mira solitario, y que en vez de productos ofrece al Erario un gravamen de consideración, cual lo acredita el estado que insertamos a continuación:

\section{Demostración aproximada de lo que cuesta al año la conservación de la plaza de Melilla.}

Estado majyor y el eclesiástico ............................ $\quad 46.140$

Hacienda militar ................................... $\quad 19.750$

Empleados del hospital $\ldots \ldots \ldots \ldots \ldots \ldots \ldots \ldots \ldots \ldots \ldots \ldots . ., \quad 38.400$

Idem. de fortificación $\ldots \ldots \ldots \ldots \ldots \ldots \ldots \ldots \ldots \ldots \ldots \ldots \ldots \ldots, \quad 11.308$

Objetos sueltos . ................................. 12.708

Mitad de la compañía de veteranos $\ldots \ldots \ldots \ldots \ldots \ldots \ldots \ldots \ldots \ldots . \quad 30.432$

Pelotón de mar ........................................ $\quad 68.060$

Utensilio de camas y luces $\ldots \ldots \ldots \ldots \ldots \ldots \ldots \ldots \ldots \ldots \ldots \ldots . \quad 36.100$

Raciones ordinarias para la guarnición y confinados, deducidas las dietas . . . 1.020 .624

Dietas y extraordinarios ............................. $\quad 70.600$

Utiles y ropas para reparar anualmente lo consumido e inutilizado en el hospital $\quad 9.000$

Atilde o conservación de la barca-correo ..................... $\quad 3.000$

Medicinas ........................................ $\quad 10.200$

Material de fortificación para reparar $\ldots \ldots \ldots \ldots \ldots \ldots \ldots \ldots \ldots . .20 .000$

Idem. para el servicio de la artillería $\ldots \ldots \ldots \ldots \ldots \ldots \ldots \ldots \ldots \ldots . \quad 95.547$

Total de reales de vellón $\ldots \ldots \ldots \ldots \ldots \ldots \ldots \ldots \ldots \ldots \ldots \ldots \ldots 1.491 .869$

Para que la plaza de Melilla adquiriese la importancia que por su situación geográfica debe tener, lo primero que en nuestro concepto debería hacerse por el Gobierno, siguiendo en ésto la opinión de todos los hombres ilustrados, sería acercarse a la corte de Marruecos y persuadir al emperador de la utilidad que a él mismo reportaría, si aceptase un tratado de Comercio con España, dando entrada a nuestros frutos y mercaderías por Melilla y Ceuta, bajo las condiciones que se estipulasen. Recabar el territorio que antes nos perteneció y que tanto perjudica a la plaza, por haber construído en él los moros algunos parapetos desde los que molestan a la guarnición. Reedificar muchos edificios que en la actualidad de nada aprovechan. Establecer aduanas en el centro de la última línea o límite español sobre el camino que desde Santiago va a la Feria, con otra porción de medidas a cual más útiles, y sobre las que no debemos extendernos por ser ajeno de ella la naturaleza de esta obra.

Fue esta ciudad en lo antiguo muy populosa con 10.000 casas dentro de sus muros, en donde residía su señor, cuya jurisdicción era dilatada. Se empleaban sus moradores en el comercio de oro e hierro, cultivando sus ricas minas y se pescaban perlas en su cala. Fue dominada por los árabes, poco antes que España, cuando se les abandonaron estos puntos avanzados, en razón de los trastornos políticos que agitaron la Península Ibérica. Sus nuevos señores etablecieron en ella gran comercio y muchas fábricas. El Corso que más tarde llegaron a practicar sobre las costas espaniolas, trajo contra ellos las armas de esta nación y quedó la costa despoblada. Los Reyes Católicos estimaron 
conveniente la restauración, y en el año 1496 salió del puerto de Sanlúcar de Barrameda una armada a las órdenes de Pedro Estopiñán, que sin resistencia alguna, ocupó sus ruinas y las fortificó inmediatamente lo bastante para que a pocos días no pudiesen los moros desalojarle de ellas. ${ }^{30}$ Volvió a edificarse el caserío reducido a mucho menor ámbito que antes había ocupado. Su primer alcalde fue Gómez Suárez, quien siguió sus fortificaciones. El duque de Medina-Sidonia la poseyó con título de Capitán General de ella por méritos que hizo con los Reyes, desde su conquista hasta 7 de junio de 1556, en cuyo tiempo proveyóles todos los empleos correspondientes a ella, a excepción del de Veedor o Contador que era de nombramiento real. ${ }^{31}$

Desde que se conquistó, empezaron las salidas de su guarnición contra los moros y los avances de estos contra ella, de modo que cada uno de sus gobernadores tiene por tales razones una larga y difusa relación de méritos. ${ }^{32}$ Asi, hacer una descripción circunstanciada de estos acontecimientos sería tocar lo interminable, pues se han estado continuamente repitiendo. Los más notables han sido el sitio que por más de $\mathbf{4 0}$ días sufrió en 1687, siendo atacada con grande impetu por un ejército numeroso; el que la pusieron en 1694, notable también proque se cree haber sido excitados a ello por los franceses con objeto de dividir las fuerzas españolas y adelantar sus conquistas en Cataluña. En 1696 sacrificaron también mucha gente los moros en el vano empeño de rendir esta plaza. ${ }^{33}$

No sólo las hostilidades musulmanas la han trabajado: terribles epidemias la han afligido también, debiendo citarse las de agosto de 1711 y noviembre de 1714; por los años de 1752 y 1754 padeció tercianas epidémicas, de que murió mucha gente.

La dilación de socorros y la incomunicación ocasionada por los temporales, la han hecho experimentar repetidas veces también los horrores del hambre. 


\section{Islas Chafarinas}

NOTA: Dependiendo las Islas Chafarinas de la ciudad de Melilla, nos parece oportuno hacer la descripción de ellas a continuación.

Las Islas Chafarinas de la que en estos días ha tomado posesión el capitán general de Granada, como pertenecientes a la parte del territorio que España posee en la costa de Africa, ${ }^{34}$ se hallan situadas a 5 millas al Este $12^{\circ}$ Sur de la punta de Quiviana, y al Sur $59^{\circ} 30^{\prime}$ Este del cabo de Tres Forcas, dista 32 millas por latitud $35^{\circ} 11^{\prime} 49^{\prime \prime}$ y longitud de $3^{\circ} 53^{\prime} 53^{\prime \prime}$.

Estas son tres; la del Oeste llamada "Congreso", la del centro "Isabel II", y la del Este "Rey"; estas dos son llanas y algo blanquinosas. Se extienden de Este a Oeste algo más de una milla y forman abrigo para toda clase de embarcaciones. La entrada entre estas islas y la costa es muy conocida, pues tanto por el Este como por el Oeste, se puede ir sin cuidado, y aunque de la punta Sur de la mayor parte de las islas se extiende una restinga de piedras, con sólo la precaución ordinaria se zafa de ellas. La isla más al Oeste es la mayor y más alta, y puede verse a distancia de 8 a 10 leguas; su parte superior aparece semejante a la copa de un sombrero. La marea se eleva muy poco, y parece depende principalmente de los vientos reinantes. El mejor fondeadero es enfrente de la isla del medio, y a la distancia de 2 cables en 9 a 10 brazas de arena y fango, demorando la punta Sur de la isla del Este al Norte $58^{\circ}$ Este, la punta Sur de la isla del Oeste - Este al Oeste $2^{\circ}$ Sur, el extremo Sudoeste de la de enmedio al Norte $47^{\circ}$ O. y el cabo de Agua al Sur. Estando situadas estas islas en lo más hondo de una grande ensenada formada por el cabo Tresforcas y el de la Guardia y tan fuera de la derrota general de la navegación, son poco frecuentadas, aunque suministran buena acogida en tiempos borrascosos. ${ }^{35} \mathrm{Al}$ abrigo de ellas se puede desembarcar en tiempos bonacibles, pero hasta ahora han estado desiertas por no prestar, entre otras circunstancias, auxilio de agua y leñas, aunque en la isla del medio se encuentra agua potable haciendo "cacinubas". 36

Altas razones de política aconsejarían al Gobierno no tener por más tiempo desiertas estas islas, cuando determinó que una expedición compuesta de los vapores de guerra "Piles" y "Vulcano", bergantín "Isabel II", y místico "Flecha", con otros cuatro buques de transporte y varias compañías de tropa mandadas por el capitán general de Granada; el Excmo. Sr. D. Francisco Serrano, partiese para dicho punto y tomase posesión de él, como lo ejecutó el día 6 de enero del corriente año (1848) ${ }^{37}$ Desembarcada la tropa y los efectos necesarios para habilitar provisionalmente aquellos apartados lugares, procedióse enseguida al bautismo de las islas, quedando con los nombres de "Isabel II" la del centro, "Rey" la del Este y "Congreso" la del Oeste. ${ }^{38}$ Después se procedió con la mayor actividad al desembarque de todos los efectos que se habían llevado, al trazado de las baterías y a todos los trabajos necesarios para plantear el establecimiento militar que por ahora debe sostener en ellas el pabellón español. El comandante de estas islas lo es el coronel de carabineros D. Vicente Ilardulla, y hacemos de él expresa mención por ser el primero que manda estas posesiones. ${ }^{39}$ En ellas se están construyendo algunas baterías y otras obras de defensa, así como algunos edificios tan necesarios para cuarteles, almacenes, depósitos de artillería y maestranza. 
La importancia principal de las islas Chafarinas consiste en hallarse situadas en frente del río Muluya, que sirve de límite a las posesiones francesas de la Argelia con el imperio de Marruecos. Este río además presentando un valle ancho y despejado hacia el interior, es sin duda alguna el punto más a propósito para dirigir una invasión hacia el interior del país, pudiendo llegarse siguiendo su curso y sin encontrar grandes obstáculos hasta "Fez", sitio real del emperador de Marruecos. Ya hemos dicho también la bondad del fondeadero que se forma entre estas islas, siendo quizá la razón que las hace más codiciadas por los franceses, quienes diferentes veces han tratado de apoderarse de ellas, y cuyas tentativas han decidido sin duda su ocupación por la España; dicho fondeadero es el único que existe desde el puerto de Mozarquivir (Orán), en cuyo intermedio tienen los franceses el punto militar de Djemma el Ghazuat, que es sólo una playa sin ningún abrigo. ${ }^{40}$ 


\section{Peñón de Vélez de la Gomera}

Vélez de la Gomera (o el Peñón de): Uno de los presidios menores o puntos fortificados que la nación cuenta en el litoral de Africa y país perteneciente al reino de Fez en el imperio de Marruecos, dependiente de la Capitania General creada nuevamente en Africa cuya capital es Ceuta.

Situación. Situada en un islote de la costa septentrional de aquella parte del globo a $34^{\circ} 40^{\prime}$ latitud Norte y a $30^{\circ} 36^{\prime}$ longitud Este del meridiano de Málaga, de donde dista 35 leguas, 75 de Orán, 25 de Melilla y 8 de Alhucemas. Por la parte del Este está 20 de Tetuán, por la del Oeste 25 de Ceuta (estas distancias no son directas sino el camino que hay que andar costeando, asi que, la distancia recta a Alhucemas, son 5 leguas aproximadamente), y 37 de Mequinez, corte del emperador de Marruecos.

Figura de la isla. La figura de la roca en que está asentada la plaza de la Gomera es en su totalidad, aproximadamente, la de un rectángulo cuyo lado mayor en dirección del Oeste - Noroeste al de Este-Sudeste, tiene 270 varas, y el menor 130, y después se prolonga al Este por un istmo de rocas de 50 varas de largo a otra peña que se llama la Isleta de unas 125 varas de larga y 50 de ancha en la parte que más. Una y otra son más altas y escarpadas por la parte del Norte, siendo la altura del piço más elevado de la plaza, donde está situada una batería llamada de la Corona, de 92 varas sobre el nivel del mar. Inferior a este picacho hay otro que se prolonga de Oeste a Sudeste como unas 200 varas, teniendo por la extremidad más elevada, que es la del Oeste, 67 a 68 varas sobre el mar, y por la que lo es menos al Sudeste, 65 varas. En el primer extremo hay una batería llamada San Julián, y en el segundo otra titulada San Miguel, entre las cuales se proyectó una cortina, pero que no se ha llevado a efecto. Todo el resto del terreno está, en general, pendiente hacia el Suroeste. La isleta tiene en su parte más elevada, que es la del Este, 26 a 27 varas sobre el mar, yendo el terreno en pendiente hasta la orilla de él.

Fortificaciones. Dada una idea general de la naturaleza y configuración del territorio entraremos en el examen de las fortificaciones y defensas. La irregularidad del Peñón, su estrechez, la poca gradación de sus diferentes dominaciones, y más que todo, el haberse ido añadiendo obras sucesivamente, ha ocasionado que no presenten las fortificaciones de esta plaza un aspecto de orden para la defensa. Todas las baterías dirigen sus fuegos al campo, a la playa enemiga y a varias partes del mar. La de San Juan puede batir la principal entrega del varadero viejo, y parece que recientemente se ha cerrado su gola con un foso y puente levadizo, proporcionando además fuegos de fusilería sobre la rampa que sale desde Carboneras, cerrándose su avenida con un rastrillo. Tomado este y pasando al segundo rastrillo del expresado varadero dentro del cual los buques no recibirían gran daño, la defensa se reduce a irse replegando las fuerzas de una en otra, de varias puertas y rastrillos defendidos por aspilleras, a saber, la del cuartel de Marina, la del torreón de Castellfullit, la que desde la calle Nueva da paso por delante del puerto de la Marina y la de San Antonio. Antes de llegar a la puerta de Castellfullit puede volarse el terreno ocupado por el enemigo, por una mina que tiene una de las entradas por el cuartel de Marina, y la otra por medio de un paso 
subterráneo que empieza en el Charcón y va a desembocar frente al mismo cuartel. Las obras de fortificación tienen un grueso variable; la muralla que corre al lo largo de los intervalos en que no hay casas, sigue el curso irregular de los edificios. La batería más dominante es la de la Corona, con disposición para 7 cañones, 2 morteros y un obús. Con una de estas piezas se bate la punta del Gomerano y mar del Oeste, con otra la punta de la Babá y entrada por el Este ${ }^{41}$ y las restantes pueden barrer el terreno intermedio, que es toda la falda del cerro del Cantil y la playa, excepto un recodo encubierto por la Puntilla. Puede batir también el fuerte de Santa Orosia, y parte del terreno de la isleta. A la anterior batería sigue la de San Julián con 4 cañones y un mortero: tiene fuegos al sitio llamado el ataque (estos que se llaman ataques están en el cerro del Cantil, y se reducen a unas pequeñas hoquedades que la naturaleza presenta detrás de las rocas y desde las que disparan los moros sin poder ofendérseles demasiado). La de San Sebastián dispuesta para 2 cañones y un mortero, bate la costa enemiga debajo del Cantil. La de San Miguel de 5 cañones y 3 morteros, bate con sus fuegos toda la playa y campo enemigo hasta la inmediacióin de la Puntilla. La de San Antonio de Padua enfila con la pieza que tiene la calle que baja a la Marina, pudiendo batir además con otras piezas la comunicación con la isleta, disparando a la vez contra la playa enemiga. La de San Francisco tiene 3 cañones y uno de ellos franquea $e l$ Fredo por ser sus fuegos muy rasantes. La de San José está situada entre las dos anteriores dentro del recinto de la maestranza; tiene 3 cañones y sus fuegos son de la mayor utilidad para batir la isleta en caso de perderse. Por último, la batería de San $J$ uan puede tener 6 cañones, 3 de los cuales baten con sus fuegos rasantes la entrada del Varadero y el Fredo hasta las inmediaciones de la isleta. Los otros tres baten la parte del Oeste y el frente.

Isleta. Esta porción de terreno que se halla separada del cuerpo principal de la plaza, con la que comunica por un puente levadizo, se halla actualmente cerrada en la parte superior por un muro aspillerado, desde su extremo inmediato al Charcón hasta el pequeño foso del fuerte de Santa Orosia. La comunicación de este recinto superior, que desciende hasta el mar, está cerrada con un rastrillo y defendida con los fuegos que se han proporcionado desde un cuerpo de guardia que existía en aquel punto. Las demás avenidas se han cerrado, dejando solo e independiente dicho recinto superior, cuya parte está en el día casi indefensa, habiéndose arruinado un muro de piedra que cubría a la altura de los hombros. El fuerte puede guarecerse con 5 cañones y un mortero; sus fuegos se dirigen a la plaza enemiga y Puntilla y flanquean perfectamente el muro construido recientemente, batiendo además el sitio en que se coloca el retén y la entrada y comunicación de la plaza a la isleta.

Varadero Viejo. Esta es la entrada principal de la plaza. Delante del rastrillo que la cierra hay una playa para varar los botes; siguiendo después una escollera de piedra hasta debajo de la batería de San Juan, y a lo largo de ella una estacada, en cuya mitad se halla un cuerpo de guardia, para cuyos fuegos se han abierto varias aspilleras que flanquean por dicho lado toda la estacada. Forma segunda línea de dicha estacada un muro aspillerado, cerrando su entrada otro rastrillo con puente levadizo y 2 fosos: en 
seguida va una rampa hasta el cuartel de Marina, encima del cual hay una ladronera o matacán; el edificio tiene aspilleras en todo su frente y cn las azoteas, cayendo una parte de aquellas sobre la puerta que da a la isleta. Tiene además troneras para cañones pedreros, los cuales pueden barrer todo el puente y comunicación con la isleta.

Varadero de San Juan. Esta es otra entrada de la plaza, y sirve para las descargas de viveres y agua. Se cierra la entrada por un rastrillo, y corre a lo largo de las escolleras una estacada que no se franquea por fuego alguno, si bien se han proyectado algunas obras con este objeto, y pasado un pequeño foso se encuentra una puerta que se comunica con la batería de San Juan y el cuerpo de guardia de la Marina.

Torreón de Castellfullit. Este paso, cerrado con doble puerta, es bastante interesante por ser el primero que se encuentra después de pasado el puente levadizo de la isleta, pues forzado por el enemigo el pequeño foso, le sería ya muy fácil entrar en la plaza, siendo entonces casi inútil la defensa de la puerta y cuerpo de guardia de la Marina, al extremo de la calle Nueva y de la puerta y batería de San Antonio. Dicho torreón tiene abiertas varias aspilleras en lo más alto del cuerpo del edificio, al que se sube por las azoteas de las casas inmediatas. Por la estrechez del sitio y disposición del terreno, es aquel de poca amplitud.

Puente y fuerte aspillerado del Caracol. Pasada la puerta de San Antonio, se llega al puente levadizo que da paso sobre un foso de 3 varas de ancho, se entra en el fuerte del Caracol con varias aspilleras y unos matacanes sobre el puente, pero todo él muy reducido, sin fuegos de flancos.

Cuarteles. Hay 2 para la guarnición extraordinaria; el de Santo Domingo con 2 cuadras capaces de contener 100 hombres, y el de San Francisco que se halla por debajo de la calle de San Antonio, con igual capacidad que el anterior. Para los confinados hay otros 2 cuarteles: el inmediato a San Francisco, donde se encierran la mayor parte, tiene 3 cuadras y puede contener 150 a 200 hombres; y el de Carboneras, junto al varadero de San Juan, capaz para 70 hombres. Para la artilleria se ha habilitado una cueva de las practicadas en la roca. La compañía fija tiene uno muy reducido en la calle Nueva, y el llamado de la Marina, que tiene una cuadra para 20 plazas y otra para almacén de pertrechos.

Almacenes. Apenas habrá uno que haya sido construído con este objeto; así es que la mayor parte están en las cuevas abiertas en las piedras. Los efectos y materiales de fortificación tienen que estar repartidos en 4 localidades distintas.

El de pólvora. No está bien dispuesto para este objeto ni se halla a prueba de bomba, estando situado inmediato al pico más elevado, lo cual le expone a los riesgos de la electricidad.

Hospital. Puede contener unas 50 camas, no siendo desventajosa su posición, pues está a un extremo de la plaza, sobre el escarpado de Santiago.

Cisternas. En el cuerpo de la plaza hay 5 que contienen unas 60.500 arrobas de 
agua, y en la isleta 2 capaces de 4.000; además se recogen aguas en los fosos de los varaderos, en una pequeña poza abierta en Castellfullit y en una alberca situada en Santiago. El gasto diario de agua se reputa en 180 arrobas, que hacen al año unas 65.000 , cantidad que se recoge en la plaza; más a pesar de esto, se llevan de España diferentes remesas.

Guarnición. En tiempos normales se compone de un destacamento que debe constar de un capitán, un teniente, un subteniente, 3 sargentos segundos, 8 cabos primeros, 5 segundos y 120 soldados. Del destacamento de la companía de los presidios menores, fuerte de 30 hombres. De 50 fusileros sacados de los confinados que tienen condenas limpias y buena conducta. Está afecto al destacamento de veteranos el pelotón de fuerza de mar de $\mathbf{2 0}$ soldados marineros. Para el servicio de la artillería hay un sargento, 6 soldados y 30 agregados de la clase de confinados. Esta guarnición es muy reducida, tanto para cubrir el servicio de la plaza, como para cuidar de los confinados, cuyo número, no debiendo exceder de 250 , llega muchas veces hasta el de 400 .

Coste que tiene la plaza a la Nación. En los sucldos del Estado Mayor de la plaza, Ministerio de Hacienda, iglesia, hospital, compañía fija, marinería y maestranza, se gastan anualmente cerca de 750.000 reales, añadiendo a éstos los correspondientes a la guarnición extraordinaria, que llegan a 300.000; el de los oficiales de ingenieros de artilleria; el surtido del hospital; coste de las estancias; botica, lo que se consume en obras de fortificación, conducción de confinados y otros objetos, puede regularse el gasto en unos 75 a 80.000 duros anuales.

Fondeadero. Entre la plaza y el campo enemigo hay un canal que se llama Fredo, que tiene entrada por el Este y Oeste. Es sitio en el que actualemente fondean los buques por unas 5 brazas de fondo de arena limpia. El Fredo se ha cegado con las arenas de riachuelo que desemboca en la playa de en frente. ${ }^{42}$ Es peligroso el surgidero con los vientos del $4^{2}$ cuadrante, con los que recala mucha mar, estando además descubierto el puerto por aquella parte, en que solo avanza una pequeña punta del cerro del Cebollero, que forma con la playa la entrada del Oeste de 600 varas de 15 a 20 brazas de fondo. Por el Este está más abrigada a causa de la mucha salida de la punta de Babá; pero pueden recalar los vientos del primer cuadrante, aunque son poco frecuentes.

Historia. ${ }^{43}$ En 1508 mandaron los Reyes Católicos al conde Pedro Navarro, que con la armada de su cargo y las galeras de Saboya, con tropas españolas e italianas, saliese a castigar los corsarios del Peñón, que infestaban las costas del reino de Granada; y habiendo llegado a su vista, intentó hacer un desembarco contra la ciudad de Vélez de la Gomera, que entonces se computaba de 7.000 vecinos. ${ }^{7}$ Luego que los africanos advirtieron la maniobra del desembarco, abandonaron el Peñón 200 hombres que había en un castillo, por lo que se apoderaron de él las tropas españolas. Desde este punto se empezó a batir la ciudad; y aunque los moros intentaron reconquistar el Peñón, no pudieron conseguirlo por entonces por la buena defensa que hizo su alcaide Juan de Villalobos. Más a pesar de ella se perdió el punto en 1522 por traición, según 
se dice, del mismo Villalobos, quedando la plaza en poder de Muley Mahomet, señor de la Gomera. En 1525 salió de Málaga el marqués de Mondéjar con una regular flota con intento de asaltar de noche por sorpresa la plaza, y no habiéndolo conseguido regresó a aquel puerto. A poco tiempo cayó el Peñón en poder del bey de Argel, quien se lo quitó a Muley, estando 38 años bajo la dominación de los Argelinos. En julio de 1563 salió de Málaga don Sancho de Leyba con 24 galeras y 5.000 hombres de desembarco, y después de varios choques con los moros, tuvo que reembarcar su gente y volver a Málaga sin haber sacado fruto de su expedición. En las Cortes celebradas en Monzón en 1564, se pidió a Felipe II se expugnasen las costas de Berbería por los incalculables daños que causaban a las de España los muchos corsarios que las infestaban, por lo cual se diputó al virrey de Cataluña, D. García de Toledo, para que tomase el mando de la expedición, compuesta de soldados españoles, piamonteses, napolitanos, sicilianos, alemanes y portugueses y varias galeras de todos los príncipes de la cristiandad. La armada salió de Málaga en agosto del citado año 1564, y después de varias maniobras, escaramuzas y fuertes ataques, llegaron a apoderarse las tropas aliadas tanto del Peñón como de la ciudad de Vélez de la Gomera, que después fue abandonada por lo costosa que era su conservación la mucha gente que se perdía, quedan reducidos los conquistadores a sólo el Peñón, que fue fortificado y bien presidiado. En 1662 se sufrió una escasez de víveres tan extremada, que llegó el caso de abrir su gobernador las puertas para que saliera el que quisiera. En 1680 sitiaron 10.000 moros al Peñón; pero habiendo sido socorrido a tiempo, tuvieron aquellos que retirarse. En 1702 mandó el emperador de Marruecos a su hijo con un ejército considerable para que unido a la gente de la comarca tomasen la plaza, que pensaban sorprender. Después de varios ataques se apoderaron los moros del fuerte que había en el campo, y habiéndolo reconquistado los españoles lo echaron a tierra para que, en caso de perderse, en lo sucesivo no pudieran desde él hostilizar la plaza. Posteriormente ha sufrido diferentes ataques, en los cuales siempre han sido rechazados los agresores, poniendo en más de una ocasión en gran aprieto a la guarnición. En 1743 se padeció en el Peñón una peste, y en 1821 la epidemia de la ficbre amarilla; traída a dicho punto desde Alhucemas; diezmó considerablemente la guarnición. Esta en diversas épocas ha sufrido hambres terribles, hasta el punto de que en 1812 se echaron al campo del moro 150 presidiarios para aligerar de gente a la que encerraba el Peñón. ${ }^{44}$ 


\section{Alhucemas}

Alhucemas (San Agustín y San Carlos de Las): isla, plaza fuerte y presidio en el mar Mediterráneo, provincia y diócesis de Cádiz (47 leguas), partido judicial de Algeciras $^{28}$ (sin embargo de su asignación a Algeciras, tanto las oficinas de cuenta y razón, como el gobernador de ella se entienden con la intendencia y capitanía general de Granada respectivamente); audiencia territorial y capitanía general de Sevilla. ${ }^{63}$

SITUADA a los $35^{\circ} 15^{\prime}$ latitud Norte, $2^{\circ} 30^{\prime} 44^{\prime \prime}$ ' longitud Este, según el derrotero del Mediterráneo 1.568 varas de la costa del Rif en el imperio de Marruecos, 2 1/2 millas del Cabo del Morro, y 5 del de Quilates en el mismo imperio. ${ }^{45}$

Goza de Clima suave y sano, no contándose otras enfermedades, aunque en pocos casos, que el escorbuto y disenterías, que tienen su principal origen en los alimentos. ${ }^{46}$

La plaza se compone de 28 CASAS de muy mala construcción, la del gobernador, que es más capaz y vistosa, tres almacenes llamados del factor y de artillería, un cuartel para la tropa, otro para los presidiarios, llamado la Pulpera, un hospital, dos pabellones en la plaza de armas, una habitación para el vigía, cinco malos calabozos y una iglesia parroquial castrense; que forman una plaza llamada del Desengaño y cuatro calles muy limpias; el hospital es uno de los mejores edificios; consta de tres salas bajas y una alta, bastante capaces y ventiladas, despensa, cocina, patio, y casa para el contralor. Tanto este establecimiento como la botica, que recibe las medicinas de la nacional de Málaga, y está al cargo de dos practicantes, se hallan muy bien servidos. La casa del vigía que se halla situada en lo más elevado del peñón, además de observar las operaciones de los moros de la costa y las novedades del mar, tiene el vigía la obligación de anunciar las horas a cuyo fin por medio de una ampollita de arena gradúan el tiempo y anuncian las horas y cuartos con dos campanas de distinto sonido. El cuartel del presidio se compone de dos cuadras sombrías y humedas y malsanas, y otra subterránea que antiguamente sirvió de enterramiento. La iglesia es de buena construcción bajo la advocación de San Agustín y San Carlos, cuyos Santos disfrutan para su culto una ración de 55 maravedies diarios; está servida por un cura castrense, que además de su dotación cobra de cada confinado 16 maravedíes mensuales para la hermandad de Animas. Hay además 5 cisternas o aljibes donde se recoge el agua suficiente para el consumo, y se hallan situadas en el cuartel de la Pulpera, en la iglesia, en el principal, en los cubos y en el huerto de la casa del gobernador, único que hay en el pueblo.

Toda la isla tiene 194 varas de largo, 98 en su mayor anchura y 501 de circunferencia; sus frentes Norte y Este son inaccesibles por naturaleza, y el último está defendido con 6 piezas; el lado Oeste tiene otra batería de 6 piezas llamada de las Vacas, y en el Sur esta la muralla real, cuya cortina sirve de paseo y cubre toda la línea del campo infiel, y está artillada con 19 piezas, todas de cobre y grueso calibre. En este lado está el fondeadero de las embarcaciones de la correspondencia y trato con España, y la entrada se verifica por una escala portátil.

Entre la plaza y el cabo del Morro hay dos islotes; uno llamado de tierra y otro de fuera o del mar, y este último está destinado para cementerio.

La inmediata costa de Africa es pintoresca por la variedad de árboles que se crian 
en las orillas del río Naccor que desemboca en la ensenada frente a la plaza, por cuya causa los berberiscos llaman a Alhucemas Hagiar-en Neccor (sepultura de Naccor), y son enemigos irreconciliables de los cristianos, sin embargo de lo cual hacen con la plaza algún comercio de trigo, cebada, frutas, miel, huevos, estambre, lana, hilo, carnes y otros efectos, cuyas mercancías las trasladan nadando metidas en pellejos de cabra y algunas veces en las lanchas de la plaza, sin que lo llegue a entender el caid de su guardia.

La población de Alhucemas, está reducida a los empleados, algunas viudas de marineros y soldados veteranos, la guarnición y el presidio. Este se compone de 68 hombres mandados por un capataz, y es destacamento del de la plaza de Ceuta, del que depende en su régimen interior. La guarnición consta de 85 hombres, un capitán, un teniente y dos subtenientes; un oficial de artillería de la clase de prácticos con un cabo o sargento y cuatro artilleros; un subalterno de las compañías de veteranos de Mclilla con 8 soldados que se llaman descubridores; algunos soldados de mar que se dedican a la pesca, ejerciendo el más antiguo el cargo de capitán del puerto; un comisario de guerra y el gobernador que es un capitán de la clase de retirados, con su secretario, que es un sargento de las compañías de veteranos de Melilla. Tanto la guarnición como el presidio y empleados gozan ración de armada y 7 cuartillos de agua diarios en verano y 5 en invierno.

Esta plaza fue tomada por los navíos españoles San Agustín y San Carlos en 28 de Agosto de 1673 sin oposición alguna, pues sólo la habitaban algunos pescadores moros, desde cuya época no ha sido formalmente inquietada; sin embargo al relevar su guardia los moros fronterizos, hacen generalmente algún disparo con una pieza de 4 que tienen en la playa, para cuya carga reúnen la pólvora que pueden, armando grande algazara si la bala dá en algún edificio. Para evitar las desgracias consiguientes, nuesto vigía da las señales convenidas, y los moradores se recogen a sus casas. Estos peligros se repiten cuando se hacen los enterramientos en el islote que sirve de cementerio, pues cuando lo advierten los moros, se colocan en una altura que domina aquel sitio y hacen un vivo fuego sobre los que conducen el cadáver. Tales demasías no están previstas en el tratado de paz con Marruecos de $1^{2}$ de marzo de 1799, al cual no están sujetos los moros de esta playa; y seria de desear que el gobierno procurase poner esta plaza al abrigo de tan repetidos insultos. ${ }^{47}$ 


\section{NOTAS}

(1) Estas eran las posesiones decimonónicas espaniolas en Marruecos, junto a "la Isla del Peregil, la de Alborán y la de Limacos o Caracoles que no están ocupadas. La tercera está en territorio de la Argelia".

MADOZ, Pascual, y, COELLO, Francisco. Pasesiones de Africa (notes y mapas), (1850), Madrid.

Para la Isla de Alborán (del pirata "Al Borany"), que da nombre actualmente al Mar que la rodea, Cfr. YUS RAMOS, Rafael, y, CABO HERNANDEZ, José Manuel (1896). Gula de la naturaleza de la región de Melilla, Melilla, p. 111-129; La Isla de Alborán: observaciones sobre mineralogía, edafología, nematodología, botónica y zoologia (1970-1972), Granada.

La Isla de "Limacos" o "Caracoles", acwal "Isla Rachgoun", es una isla de Argelia, adyacente a la provincia de Orán y situada a $2 \mathrm{Km}$. del litoral, frente a la desembocadura del Tafna, a los $35^{\circ} 19^{\circ} 28^{\prime \prime}$ " de latitud Norte y $1^{\circ} 18^{\circ} 44^{\prime \prime}$ de longitud Oeste de Greenwich. Tiene $800 \mathrm{~m}$. de largo por $200 \mathrm{~m}$. de ancho y 60 de altura máxima.

Corresponde a la "Insula Acra" de los romanos.

Entre la isla y la costa queda un pequeño fondeadero. Los fondos son de más de $21 \mathrm{~m}$.

Cfr. ENCICLOPEDIA Universal Ilustrada Europeo-Americana (1923), Barcelona, Tomo XLIX, p. 114.

(2) Pascual Madoz desarrolla en el tomo VI (1847) de su Diccionario, la voz "Ceuta" (p. 372-380), con una información muy interesante $e$ inédita, con especial atención al establecimiento del presidio.

(3) MORALES Y MENDIGUTTA, Gabriel de (1920). Efemérides y curiosidades: Melilla, Peñón y Alhucemas. Melilla, p. 82.

(4) PIRALA, Antonia (1868). Ilistoria de la Guerra Civil y de los partidos liberal y carlista. Madrid, (ed. 1984). Cfr. especialmente el tomo V (1838-1839): Insurrección en Alhucemas y Melilla, p. 231-234.

También GARCIA FIGUERAS, Tomás (1971). Un documento importante de la ocupación carlista de Melilla. "Africa", nl 360, Madrid, s. p.: MORALES Y MENDIGUTIA, Gabriel de Op. cit., p. 42; 44; 55; y. 62.

(5) MORO, José Me (1983). La desamortización de Madoz. "Historia 16" ñ 84, Madrid, p. 58-64.

(6) Cfr. GUTIERREZ CONTRERAS, Francisco (1977-1978). Notes sobre el Africanismo a fines del XIX, "Anuario de Historia Moderna y Contemporánea", números 4 y 5, Granada, p. 326.

(7) Cfr. VALDERRAMA MARTINEZ, Femando (1983). La presencia de España en el Norte de Africa, Anexo $n^{2} 1$ de la revista "Publicaciones", Melilla, p. 169-186.

(8) En 1767 el Conde de Aranda emitió dictamen (a la vuelta de la embajada de Jorge Juan a Marruecos) con propuesta de demolición de los presidios. Una Junta dictaminó que "Melilla no tenía puento; que sólo lanchas podían atracar con peligro; que la plaza estaba dominada por todas partes, sin tener a prueba de bormbas más que el almacén de pólvora, y que el día en que los marroquíes dispusieran de artillería, sería imposible la defensa. No obstante, la mayoría de los examinadores voto la conservación, que, por consecuencia, quedó decidida".

Cfr. FERNANDEZ DURO, Cesáreo (1895-1903). Armada española desde la unión de Castilla y Aragón, Madrid (ed. 1973), v. 7. p. 176-178.

(9) Coincide ampliamente Madoz con Aranda, quien, desde su embajada en París, insiste en su idea de abandono de las Plazas y aconseja (1775) volar Melilla y el Peñón, "piezas de mucho embarazo y de ninguna utilidad". Enuncia, como alternativa, ocupar las Islas Chafarinas, "donde se podia formar el mejor puerto de toda Africa en el Mediterráneo". Ibidem, p. 178.

(10) MOGA ROMERO, Vicente (1987). Juan Antonio de Estrada: historiador melillense del siglo XVIII. "Conoce tu ciudad", ne 1, Melilla, s. p.

(11) El Imperio de Marruecos es definido por los geografos dentro de la "Berberia", junto a la "Regencia de Trípoli". "Argelia" o "Argeria" y viene descrito como la monarquía "más poderosa de Africa, cuenta con siete millones de habitantes. El país, cortado por varias ramificaciones del Allas, comprende grandes llanuras feracísimas, pero mal cultivadas, y que riegan los rfos Sebú, Burgel, Umm, Tensift y otros. Sus moradores, muy morenos y negros, forman muchas tribus o kabilas casi independientes. En general son bábaros, ignorantes y fanáticos. Se dedican al cultivo de pieles y tejidos, y hacen mucho tráfico en frutos del pais y ganados. Tiene por capital a Marrecos, ciudad grande pero de calles estrechas y sucias, longitud $3^{\circ} 28^{\prime}$ ' Oeste, latitud $30^{\circ} 32^{\prime}$ None. El Emperador reside en Mequinez, ciudad muy linda. Fez, capital del reino del mismo nombre, es grande, con bellos jardines. Ressant, con deliciosa campiña. Sus y Tafilete, 
plazas fuertes. Segelmesa, abundante en ricos dátiles. Tánger, Mogador, Salé, Rabat, Larache, Saffi, Mazagán y Tetuán, puertos célcbres por su comercio en granos, seda, lana, accitc, naranjas y frutas, pieles y ganados. El pequeño establecimiento de Santa Cruz la pequeña en el Atlántico, al frente de Canarias se ha cedido a los españoles. En la costa septentrional se hallan los presidios españoles de Ceuta, Vélez, etc. (VERDEJO, 1865, p. 385-386).

El análisis sociológico de la población manifiesta tanto su desconocimiento como las caracterizacioncs peyorativas, que, podían ser seguramente las más extendidas entre los europeos: "La población (de la Berbería) consiste en una mezcla de moros, bereberes, kabilas, negros, riferios, árabes, judíos y turcos. Los berberiscos son en general muy morenos, bien formados, ágiles, fanáticos, ignorantes, poco inclinados a las artes y ciencias, avaros, lascivos, crueles, dados a la piratería, y que desconociendo cl derecho de gentes, tratan a los prisioneros con endecible crucldad" (VERDEJO, 1865, p. 384).

Tres cuartas partes de sus habitantes (de Marruecos) viven en tiendas en las praderas y los llanos, profesan el mahometismo y gimen bajo el gobiemo más despótico y bárbaro de la tierra" (DIANA, 1859. p. 20).

La realidad es que subyace en estos juicios de valor la prepotencia del hombre blanco, definida por Kipling, y que olvida la realidad de un pais que soporta una fuerte presión foránea, que busca la apertura a sus intereses comerciales. Así, frente a los intentos reformistas de los sultanes en los aspectos administrativos, militares, económicos y financieros (BRIGNON, 1982, P. 314-321), las potencias extranjeras van a consolidar su penetración en el Imperio de Marnecos desde los inicios de la segunda milad del siglo XIX, con la firma de tratados comerciales (1856, Gran Bretaña; 1860-61, España; 1863, Francia) (BRIGNON, 1982, p. 289-292).

Los esfuerzos del Makhzen se encaminan a resistir activamente la penetración europea, que queda establecida claramente en 1880. "La conferencia de Madrid marca prácticamente el fin de la independencia de Marruecos" (BRIGNON, 1982, p. 298).

Cfr. VERDEJO PAEZ, Francisco (1865). Principias de geografía astronómica, fisica y política. Madrid.

DIANA, Manuel Juan (1859). Un prisionero en el Rif. Memorias del ayudate Alvarez. Madrid.

BRIGNON, Jean... (et. al.) (1982). Histoire du Maroc. Hatier.

(12) Por Real Decreto de 18 de diciembre de 1847 se crea la Capitanía General de las Posesiones de Africa. Comprendía las 4 plazas del norte de marruecos, con "Ceuta" como capital agregándoseles más tarde las "Islas Chafarinas". Poca fue la vida de esta Capitanía, ya que por R.D. de 25 de febrero de 1851 se suprime y las Plazas vueiven a la dependencia de las Capitanías Generales de Granada y de Andalucía.

La primera englobaba Almería, Granada, Jaén, Málaga y los "presidios de Africa"-excepto "Ceuta"-. con capital en Granada. Por su parte, la Capitanía General de Andalucía englobaba a Bajajoz, Cáceres, Cádiz, Córdoba, Huelva, Sevilla, Campo de Gibraltar y la "Comandancia General de Ceuta", con sede en Sevilla.

Del gobemador de "Melilla" dependían directamente "Peñón de Vélez de la Gomera", "Alhucemas" y "Chafarinas" (Reales Ordenes de febrero y mayo de 1855). Por su parte, el gobernador militar de "Melilla" quedaba sujeto al Reglamento para el Cucrpo de Estado Mayor de Plaza (R.D. 21 de diciembre de 1852).

En cuanto a las "plazas fuertes", existían 81 en toda España, clasificadas en cinco categorías (R.D. 13 de septiembre de 1842). Las capitales de distritos militares eran declaradas "plazas de guerra", en razón de sus especiales circunstancias. Ya en 1852 se crea y reglamenta la Dirección General de los Cuerpos de Estados Mayores de Provincias y Plazas.

Dentro de la Capitanía General de Granada, "Melilla" era "plaza fuerte de segunda clase" (mandadas por un brigadier y un comandante, bajo los títulos de gobemador y sargento mayor respectivamente); el "Peñón de Vélez", "Alhucemas" y "Chafarinas" eran "plazas fuertes de tercera clase", al mando de un jefe, con el ú́tulo de gobemador. Además el "establecimiento penal de Melilla" estaba considerado de "quinta clase" y mandado por un teniente, con el útulo de comandante.

Cfr. FERNANDEZ BASTARRECHE, Femando (1976). La división terrilorial militar de Andalucía en el sexenio revolucionario (1868-1874). Actas del Primer Congreso de Historia de Andalucía", Córdoba, Tomo I, p. $501-508$.

La adscripción al partido judicial de Algeciras era meramente nominal ya que los presidios quedaban sometidos todos al fuero de guerra.

(13) Dado que en esta época no habia un acuerdo intemacionalmente aceptado sobre la adopción de un 
meridiano de referencia, los geógrafos utilizaban aquellos que querían. En este caso, la longitud está tomada sobre el Meridiano de Madrid. La legua equivale a 20.000 pies castellanos. 1 pie tiene 0,278 metros y 1 vara castellana, 0,835 metros. (VERDEJO, Op. cit. p. 68-69).

(14) Marruecos, es decir Marrakesh, la antigua capital de Marruecos.

(15) Cfr. DOMINGUEZ LLOSA, Santiago (1987). Apuntes sobre la propiedad rústica y urbana de Melilla en el siglo XIX. "Trápana: Revista de la Asociación de Estudios Melillenses", Melilla, $n^{9} 1, p .29-34$ y Anexo.

(16) Madoz utiliza para las tribus la denominación partidos o alcalahías, y los nombres por su denominación árabe Mazuce (Mazuza), Benciferor (Beni-Buifrur), Bene-Usides (Beni-Sidel), Benézicar (Beni-Sicar) y Bene-Gullafar (Beni-Bugafar). En realidad, al ser tribus bereberes, de la región oriental del Rif, se denominan en su lengua (Tarifit, o, Zamazigz), Imazujen, Ait Bu Ifrur, Ait Sider, Ait-Shishar y Ait-Bu Yafar, y constituyen una confederación denominada "iqar iyen", de tipo tribal, que a su vez presenta fracciones y grupos.

La mayor parte del territorio igar'iyen —al que Madoz parece denominar "Garett"- está constituído por tres montañas: los macizos de Tres Frocas, Ibel Gourougou y el del Uixan. Al Sur y al Este quedan cercadas por las llanuras de Gareb y de Bu-Areg. Además, a escasos kilómetros al Este de Melilla —en plena tribu Imazujen - se encuentra la laguna de la Mar Chica, con una restinga que la separa del Mediterráneo, de $24 \mathrm{~km}$. de longitud (JAMOUS, 1981, p. 13-17).

Las relaciones con estas kabilas era vitales para "Melilla". Aunque estaban bajo el dominio teórico del Emperador de Marruecos (Moulay Abderramán, 1822-1859) de la dinasúa alauita (BRIGNON, 1967, p. 252). En realidad escapaban a su dominio territorial. Ello a pesar de estipulaciones como las del Convenio signado por España y Marruecos en 1845 y que recogía "que las órdenes del Sultán evitarían las agresiones de los fronterizos" (PEZZI, 1983, P. 131).

La realidad parece ser la impotencia del Sultán para garantizar la seguridad del "Presidio", que se había recogido de forma expresa en el anterior Tratado de 1799, en que se dio "facultad en las plazas de "Melilla", "Peñon" y "Alhucemas", de usar contra los fronterizos del fuego de fusil y cañón para contener sus dernasías, sin que por ello se entendiese quebrantada la paz con Marruecos" (PEZZI, 1893, p. 125-127).

Además el "Bajá del Rif", a quien se encomienda el gobiemo de la región, no suele conocerla, y se limita a recaudar el tributo anual ("garramá") para el Tesoro Imperial. "Las verdaderas autoridades son los mohkanden o cabos de Kabila a quienes siguen en importancia los jefes de pueblo o "cabos chicos" (PEZZI, 1893, p. 181-182).

Cfr. JAMOUS, Raymond (1981). Honneur et baraka: les structures sociales traditionnelles dans le Rif, París; BRIGNON, Jean... (et al) (1982). Op. cit.; PEZZI, Rafael (1893). Los presidios menores de Africa y la influencia española en el Rif. Madrid.

La especial dificultad que tradicionalmente ha presentado la población fronteriza cercana a "Melilla", y. por extensión, el "Rif", ha generado dudas sobre la cohesión del Imperio de Mamuecos y su impotencia sobre el territorio que se ha llamado rebelde ("Blad-es-siba"). La postura de una cohesión del Imperio de Marruecos es defendida por AYACHE, Germain (1983). Etudes d'histoire marocaine, Rabat, p. 184-185.

En cuanto a la caracterización tribal del "Rif", Cfr. HART, David (1983). Los bereberes marroquies: dialectos, organización tribal $e$ instiluciones sociales. "Publicaciones de la Escuela Universitaria de Magisterio de Melilla", $\mathrm{n}^{\circ}$ extraordinario dedicado a las conclusiones de las "Primeras Jomadas de Cultura Hispano-Bereber: Aproximación a las culturas mediterráneas del norte de Africa", Tomo I, Melilla, p. 145-157.

Un estudio fisiográfico, con recopilación y exposición de datos ecológicos, en: YUS RAMOS, Rafael, CABO HERNANDEZ, José Manuel (1986). Op. cit.

Madoz utiliza la expresión "Ref", en lugar de "Rir" (literalmente significa en lenguaje árabe "campo"). También suele verse denominado "Riff". Lo más adecuado es denominarlo "El Rif" (Er-Rif).

"El Riff", o región montañosa, dependiente de Marruecos, corre a lo largo del Mediterráneo sobre una longitud de 330 kilómetros y una anchura media de unos 50. Presenta una serie no interrumpida de montafias, que conocemos imperfectamente; son continuación de las de Argelia, y al parecer análogas a la zona montanfosa comprendida entre Cherchel y Tenes, a quienes los berberiscos dan también el nombre de RiFF.

Todo este territorio está poblado de aldeas aquí y allá esparcidas y toscas y pobremente fabricadas. Los habitantes en tribus errantes y salvajes, no reconocen la autoridad del Sultán, que muy raras veces, y a poder de un fuerte ejército, consigue hacer efectiva la derrama o contribución. Hoy está dividida en distin- 
tas kabilas o tribus, siendo las principales las que se hallan en el campo que ellos llaman de kalaya, al frente de la plaza de Melilla.

Estas kabilas de 4.000 a 3.000 hombres cada una, están a las órdenes de cinco jefes o "Moscamdeness", y se llaman siempre, sea quien fuere el jefe que las mande, Mazuza, Benibuyfuror, Benibuyllafar, Benisidel y Benisicar. Hablan un árabe corrompido, o por mejor decir, un dialecto particular. Su frecuente trato con los escapados de Melilla a su campo les ha dado conocimiento de nuestra lengua, que entienden y hablan, aunque imperfectamente. Melilla, situada en la extremidad de su campo, es la perla que desean poseer, $y$ a la que dedican sus constantes afanes".

Cfr. DIANA, Manuel Juan, Op. cit., p. 17-19.

Esta es la visión que presenta, el Tercer Ayudante de la Plaza de Melilla. Francisco Alvarez Jardón, hecho prisionero en una emboscada tendida por los confidentes del presidio. Maimon el Arbi y Bondicl el Alto, el 30 de septiembre de 1858 , junto a 20 confinados.

Cautivo, fue conducido a Fez por el jefe de la kabila de Beni-Sidel. Sidi Mohammed.

El 22 de marzo de 1859 fue entregado en la Alcazaba de Tánger, al representante de España, Juan Blanco del Valle, y embarcado el día 25 para Melilla, donde obtendría licencia por enfermedad. Esta es la historia que narra Manuel Juan Diana en la obra ya citada anteriormente.

Cfr. MORALES Y MENDIGUTIA. Gabricl de (1920), Op. cit. passim.

(17) La distancia de seguridad -mínimo de tiro de fusil- era básica y no se conseguirá hasta la firma del Tratado de Tetuán de 1860 , que va a posibilitar la recuperación del territorio perdido a mediados del S. XVII. Es evidente que 1860 inaugura una nueva etapa en la historia de "Mclilla" caracterizada por su expansión exterior (MORALES, 1909) (PEREYRA, 1982, p. 130).

En efecto, la "Melilla" del siglo XIX, hasta 1860, se nos presenta como "una plaza hostigada" (SARO, 1985), "Melilla" queda abandonada a su propia suerte (MORALES, 1909, p. 12), sumida en un aniquilamiento pérsistente desde el último tercio del siglo XVII. Los primeros síntomas de recuperación se manifiestan en la época del gobemador Manuel Buceta del Villar (1854-1856; 1858-1860). Con Buceta se inicia el fin de la penuria de la "Plaza" cercada en sus recintos amurallados, con partes casi diarios de muertos por "bala mora", de "casco de bomba", de "pedrada de monero", o a "golpes de gumía". (MORALES, 1920, passim).

Cfr. MORALES MENDICUTIA, Gabriel (1909). Dalos para la Historia de Melilla, Melilla; PEREYRA, Juan Carlos (1982). Introducción al estudio de la política exterior de España (siglos XIX y $X X$ ), Madrid; SARO GANDARILLAS, Francisco, BARRIO FERNANDEZ DE LUCO, Claudio (1985) Aproximación a la Historia de Melilla, Melilla, Ms. inédito.

(18) En la actualidad distinguimos cuatro recintos, correspondiendo el denominado por Madoz como tercer recinto, al actual cuarto recinto en su mayor parte. Es decir, la "Alcazaba". Esta, con muchas dificultades conserva aún los fuertes de Victoria Grande y Victoria Chica, el fuerte del Rosario, semidertuido; parcialmente la batería que defendía el foso de San Miguel y el rastrillo; y algo de San Carlos, como las cañoneras y restos de la cortadura. Cfr. BRAVO NIETO, Antonio, SAEZ CAZORLA, Jesús (1987). La Alcazaba de Melilla: Das siglos de historia, Melilla, Ms. inédito.

(19) Los cañones de bronce y de hierro y las culebrinas, miden sus calibres en libras ( 1 libra $=16$ onzas $=460$ gr.) correspondientes al peso de las bombas que podían proyectar. Por su parte, moneros y obuses miden sus calibres en pulgadas de las bocas de fuego ( 1 pie $=12$ pulgadas $=278 \mathrm{~mm}$.)

Cfr. VIGON, Jorge (1947). Historia de la artillería española. Madrid, 3v.

Para una comparación de la evolución de la artillería en la Plaza de Melilla, Cfr. SANZ SAMPELAYO, Juan (1977-1978), Los presidios españoles del norte de Africa y su aprovisionamiento de víveres a fines de siglo XVIII, "Anuario de Historia Modema y Contemporánea, números 4 y 5, Granada, p. 103-105.

(20) "Melilla" ha sido plaza propicia a los terremotos, especialmente significativo fue el año de 1792, sufriendo solamente el mes de enero más de veinte temblores de tierra. Temporales de levante, desbordamientos del Río de Oro, como el del 22 de febrero de 1846 en que se desbordó y arrastró un torreón del fuerte de San Jorge, sequías impenitentes, hacían aún más complicada la vida de los moradores de la plaza.

La violencia de los terremotos era palpable. El del día 11 de febrero de 1848 cerró incluso la boca de la Mar Chica (MORALES, 1920, p. 37). La de los temporales no es menor, arrojando buques fuera del alcance de la "Plaza", causando naufragios, y dificultando el aprovisionamiento y las comunicaciones.

Cfr. MORALES Y MENDICUTIA, Gabriel de (1920). Op. cit. passim.

(21) Iglesia (1657); Hospital Real (1758) y Aljibes (1571) constituyen obras señeras de la "Plaza". Ac- 
tualmente se conservan, aunque el Hospital de la Sangre lo hace en estado deplorable.

En cuanto a las cuevas jugaban un papel importante durante los asedios, siendo utilizadas como almacenes de viveres y efectos durante los periodos de paz (MORALES, 1920, p. 249).

(22) El cementerio de San Carlos se construyó en 1796-1797, perdurando hasta 1892 en que comenzaron a trasladarse los enterramientos al nuevo cementerio de la Purísima Concepción, en el campo exterior a los recintos (MORALES, 1920, p. 314-319).

(23) El "Rlo de Oro" desembocaba al pie de las murallas de "Melilla", hasta el desvío de su cauce (1871). El río era un elemento de apoyo de los ataques de los fronterizos a la Plaza. En efecto, estos construían los denominados "ataques", es decir, "unos parapetos de tierra y argamasa, reforzados y ocultos a la vista de la Plaza por cañas, que servían a los fronterizos para hostilizarla y defenderse de las salidas de la guamición... (Además) era impotente para destruirlos nuestra artillería del 24". (MORALES, 1920, p. 243-244).

Las salidas de la guamición para destruir estos ataques del río eran frecuentes. A veces se lograba destruir los ataques y, a veces, no. Así, por ejemplo, el 4 de agosto de 1850 "durante una ausencia de los moros, ocuparon sus ataques inmediatos a San Miguel 12 confinados y cuando aquellos regresaron, rompieron el fuego sobre ellos, haciéndoles bajas. Los confinados se retiraron sin novedad y subieron al fuerte por medio de cuerdas previamente sujetas a los muros por gruesos clavos" (MORALES, 1920, p. 145).

La vegetación que lindaba el río también quedaba convertida en un elemento a considerar. Así, el 19 de agosto de 1852 "se quemaron con camisas embreadas los cañaverales próximos a la plaza, en los cuales se apostaban los fronterizos" (MORALES, 1920, p. 153).

La denominación "Río de Oro" la explica Estrada, "por algunas pintas, que suelen extraer(se) de las arenas con este precioso metal". (ESTRADA, 1748, p. 491).

Pero el río no siempre ha tenido esta denominación. En el Mapa de "Territorio de Melilla" que se conserva en el Archivo Histórico Militar de Segovia, del año 1692, se le llama "Río de la Plata", mientras que en algunos mapas del siglo XVII, como el conocido del Sitio de Melilla de 1774-1775, arribuido a Francisco de Miranda, se le señala con el nombre de "Río de Melilla".

En la sctualidad, conserva el nombre de "Río de Oro", pero también recibe diversos nombres, por los lugareños de los alrededores de la ciudad, según el lugar por el que circula. Así, en el nacimiento del río, se conoce como "Igzar Imrabden" o río de los morabitos (santos bereberes), denotando quizá el topónimo con que los pobladores de los aduares vecinos, denominan al Monte Gurugú, en el que nace, y que llaman "Sidi Hamed el Hadj", nombre del morabito o marabut que está enterrado, y tiene su morabo, en una de las cimas de este sistema montañoso. También se conoció al Monte Gurugú (o Gourougou, en su deformación afrancesada) como Monte Caramús, entroncándolo quizá, y esto sigue dentro del terreno de la hipótesis, con el clan de "el-karmudi", establecido en la región (Guelaia).

Por último, ya en su paso por Farhana, el río se conoce como "mduar" y también como "Arroyo Mezquita". Como "Meduar" nos dice G. de Morales que era llamado el río "por los moros, (que significa) el que serpentea, el que rodea, el que describe un círculo", (MORALES, 1920, p. 296).

Lo que está fuera de toda hipótesis es que nuestro río propiciaba la aparición de fiebres palúdicas, al ser cegada su boca y empantanarse sus aguas. Así, en junio de 1847 "afligía a la plaza una epidemia de fiebres palúdicas, ocasionadas por las emanaciones del nó" (MORALES, 1920, p. 107). Había pues que permitir el libre paso del agua. De este modo se constatan hechos como la salida de 23 confinados, el 25 de junio de 1853, que "destruyeron la barra que impedía el desagüe del Río Oro y el ataque de este nombre" (MORALES, 1920, p. 114).

La falta de víveres y todo tipo de pertrechos también tuvo que influir en la resistencia biológica de la población. De muestra valga la llegada a Melilla el 3 de mayo de 1844 de la barca de Manuel Lafont, con víveres, "que salvó a la Plaza de los horrores del hambre que se dejaba ya sentir" (MORALES, 1920, p. 88). A veces, el socorro venía de la forma más impensada, casi milagrosa y en forma de maná. Así, el 18 de septiembre de 1833 "pas6 por Melilla una inmensa bandada de codomices, cayendo gran número en las calles y azoteas" (MORALES, 1920, p. 175).

El 30 de julio de 1855 "un cárabo apresado importó la epidemia colérica en la Plaza, siendo preciso establecer un hospital en la Alcazaba. 22 personas murieron desde este día al 5 de agosto en que terminó radicalmente la terrible enfermedad, dícese que después de un violentísimo temporal de Poniente" (MORALES, 1920, p. 139). 
"En el curso de todos estos años las arenas que arrastraba (cl Río de Oro) iban formando el Mantelete, del cual no existian ni vestigios en los primeros tiempos de la conquista y aún en los planos de principios del siglo XVIII llegaba el mar hasta el mismo pie de las rocas sobre que se asientan las murallas que circundan la antigüa fortaleza desde el Torreón de la Cal hasta el foso hoy llamado de los Galápagos" (MORALES, 1920, p. 294).

Cfr. ESTRADA, Juan Antonio de (1748). Población general de España, Madrid, 3v.

(24) Madoz parece anunciar la futura actividad comercial de la Plaza, fomentada por la declaración de puentos francos de Melilla, Chafarinas y Ceuta el 18 de mayo de 1863. Con ello se da inicio a la penetración comercial espaniola en Marruecos, coincidiendo con la europea (BRIGNON, 1982, p. 284-321).

Con anterioridad, ya en 1799, se había firmado un tratado, y se había asignado a los Cinco Gremios Mayores de Madrid, su monopolio y "el privilegio exclusivo para hacer el comercio entre estos mis reinos (Cartos III) y el de Marneccos (Moulay Slimane), de los granos y demás frutos de este país".

Los Cinco Gremios Mayores de Madrid, también abastecerían a los Presidios, hasta su pase a los abastecedores malagueños. Posteriomente el Convenio de Larache (1845) dará paso a una mejora de la situación, desde el punto de vista europeo, que quedará ya plasmada en el Tratado de 1860.

De otra parte, entre los artículos que cita en su relación Madoz, aparecen algunos que indican ciena ósmosis de las costumbres entre los melillanos (topónimo de habitante de Melilla en el siglo XIX) y los kabileños fronterizos. Así, el uso de jaiques y de babuchas, que conocemos por autos e inventarios de testamentarfa de la época.

El jaique ha sido descrito magnificamente por Alí Bey el Abbassi (Domingo Badía y Leblich) en sus "Viajes por Africa" a inicios del siglo XIX:

"El traje de los habitantes es camisa con mangas anchisimas, enormes calzones de tela blanca, almilla o chaquetilla de lana, bonete rojo y puntiagudo; la mayor parte llevan alrededor de éste una tela o musclina blanca que forma el turbante. El hhaik los envuelve enteramente y cubre su cabeza a manera de cogulla; a vezes el capote o albomoz blanco con su capucha encima del hhaik, y las babuchas o pantuflos amarillos. No falta tampoco quien en lugar de la chaquetilla lleva un cafian o levita langa abrochada por delante de alto a bajo con mangas mui anchas; pero no tan largas como los de los caftanes turcos. Todos llevan cinuron de lana o seda.

Las mujeres se presentan siempre tan completamente envueltas, que con dificultad se vislumbra un ojo en el fondo de un pliegue de su enorme hhaik; su calzado consiste en grandes babuchas coloradas, pero siempre sin medias como los hombres. Cuando llevan nitio u oura carga, siempre es sobre las espaldas, de modo que es imposible verles las manos.

El vestido de los niños consiste en una simple túnica con cinturón.

El albomoz sobre el hhaik es el traje de ceremonia de los talbes o literatos, los imams o gefes de las mezquitas, y fakihs o doctores de la lei".

Cfr. BADIA Y LEBLICH. Domingo (1836). Viajes por Africa y Asia, Paris, Tomo I, p. 21-22.

En cuanto a la referencia de Madoz a la ciudad de Mogador como centro comercial, hay que decir que efectivamente Mogador (actual Essaouira) era una ciudad eminentemente comercial, "con 16.000 habitantes, dedicados en su mayor parte al comercio de gomas, lanas, pieles y cera... Se divide la ciudad en dos partes: en la una, llamada la ciudadela, residen los agentes consulares de las naciones europeas, y el Bajá: en la otra, los hebreos, y las dos están rodeadas de murallas. El puento está al Mediodía de la ciudad en una islita como de dos millas de circunferencia, y es de poquísima importancia por el reflujo".

Cfr. DLANA, Manuel Juan (1859), Op. cit. p. 308-309.

(25) La importancia de los muelles o desembarcaderos era tremenda. Melilla no tuvo puerto hasta la primera década del siglo XX, utilizando hasta entonces los varaderos más o menos naturales a uno y otro lado de la Península calcárea que sostenía la Plaza. Ello conllevó numerosas dificultades para los faluchos de la Plaza y, en general, para la supervivencia de los moradores. Estos dependían de las embarcaciones absolutamente ya que en esta Epoca Melilla, en el interior de sus recintos amurallados era practicamente una isla, y la salida al exterior en busca de leña, o simplemente a pescar o a coger caracoles solía costar cara (MORALES, 1920).

Los temporales de Levante también incidían en el aislamiento de la Plaza y en muchas ocasiones el desembarco de pasajeros y vituallas era muy arriesgado. En estas ocasiones destacaba el celo de los pelotones de Mar, que bajo el nombre de Companía de Mar ha pervivido hasta 1987. La piratería de los fronterizos y el constante avistamiento de los cárabos kabileños contribuian a minar la situación, ya de por 
sí difícil de la Plaza. Pero no será hasta inicios del siglo XX, cuando se haga próxima la realidad de un puerto capaz para Melilla. En tomo al tema se generará una literatura interesada, como es el caso de Manuel Sánchez de Valenzuela, secretario contador de la Junta de Obras del Puerto, para quien, contar con el puerto "supone contar con el resguardo necesario para los buques de alto bordo que hoy nos visitan". Para Valenzuela, el puerto sería la piedra angular del desarrollo de Melilla y además, se convierte en portavoz, uno más, de la próxima influencia española en el Rif, que comportaría la explotación de los criaderos de hierro y plomo; el incremento del prestigio y, a la par, el aumento de las transacciones comerciales con las kabilas; y, por supuesto, la expansión de los dominios españoles.

Cfr. SANCHEZ DE VALENZUELA, Manuel de (1904). Una idea sobre el puerto de Melitla. Málaga, p. 7-8.

(26) Puede ser de interts resumir brevemente las etapas históricas que ha vivido Melilla desde su ocupación hasta inicios del siglo XX:

Historia de Melilla (1497-1909): Etapas.-

19) "Conquista y expansión" (1497 - c. 1666): se construyen fuertes avanzados y se logra mantener la Plaza a la distancia de seguridad de 1.000 metros;

29) "Decadencia" (c. 1667 - Mediados s. XIX): Caen los fuertes exteriores. La plaza queda reducida al recinto amurallado, soportando duros asedios;

3) "Transición" (Mediados s. XIX - 1893): Recuperación. Se inicia con el gobiemo del brigadier Buceta (1854). La Plaza de guerra pone los primeros cimientos de la futura Plaza comercial (Puerto franco, 1863; Aduana marroquí, 1866);

4') "Engrandecimiento" (1893-1909).

(MORALES, 1909, p. 11-12)

(27) "Fraxana", actual Farhana (en árabe, 'slegria'), en las inmediaciones de Melilla, con restos de la alcazaba mandada construir por el príncipe Muley El Abbas, en 1863, durante el reinado del alauita Mohammed IV (1859-1873).

(MORALES, 1920, p. 217).

La alcazaba fue volada y practicamente destruida por el Roghi Bu-Hamara, ya a inicios del siglo XX.

Cfr. ARQUES, Enrique (1966). Las adelantadas de España, Madrid, p. 151.

(28) Antonio Villalba y Angulo, gobemador de Melilla (1732-1757), natural de Orán, "hombre versado y práctico en la Guerra de los Moros" (ESTRADA, 1748, p. 523). Es elogiado por la toma de "El Cubo", o "Ataque Alto", lugar clave para el hostigamiento de la Plaza, y sobre el que construyó, a sus órdenes, el ingeniero Juan Zermeño, en 1736, un fuerte triangular, al que se dio el nombre de "Victoria".

Ambos personajes, gobemador $e$ ingeniero son cantados por un poeta anónimo por la toma de "El Cubo" (Victoria Chica), y que describe en octavas la grandeza de sus hazañas.

Expresión lírica de la toma de El Cubo (c. 1734-1736), (s.l.).

(29) Cfr. Lista de alcaldes de Melilla en: MIR BERLANGA, Francisco (1977). Melilla en los pasadas siglos y otras historias, Melilla, p. 173-177.

(30) En realidad la fecha de la ocupación es 17 de septiembre de 1497. La cifra errónea la recogen entre otros, PEZZI (1893); MORALES (1909-1920); etc. Madoz toma la fecha del libro de ESTRADA (1748, p. $497-$ 499), al que copia literalmente en todo este capítulo:

Fue esta ciudad (Melilla) en sus primeros tiempos populosa ciudad, y de gente rica, con más de 10.000 casas dentro de sus muros, donde residía el Serior de ellas, con terminos muy largos, grandes Minas de Oro e Hierro..." (p. 497 y ss.).

A su vez, ESTRADA toma estos datos de: MARMOL CARVAJAL, Luis de (1573). Descripción general de Africa, Madrid, (s.a.), T. 1.

Cfr. GARCIA FIGUERAS, Tomás, SANCHO MAYI, Hipolito, FERNANDEZ DE CASTRO Y PEDREDRA, Rafael (1947). Conmemoración del $450^{\circ}$ Aniversario de la conquista de Melilla, Melilla.

(31) En 1556 la Casa de Medina-Sidonia cedio a la Corona la plaza de Melilla, que hasta entonces detentaba en virtud de asientos o capitulaciones (FERNANDEZ DE CASTRO, 1945, p. 503-519). Hasta entonces era el "Veedor" el representante real en la Plaza, no siendo pocas las fricciones con el gobemador, cuyas atribuciones no admitian cortapisas.

Cfr. DE CASTRIES, H. de (1921). Les souces inedites de l'histoire du Maroc, Archives et Bibliotheques d'Espagne, Paris-Madrid, T. 1. Especialmente el estudio introductorio sobre la Melilla del siglo XVI 
que en nuestra opinión es lo mejor escrito sobre este período: "Melilla au XVI0 siècle", Tomo I, p. IXXVIII.

(32) "Las contínuas embestidas de los moros fronterizos a la plaza de Melilla, contestadas a veces por impetuosas salidas de la guamición, como las de 16 de Marzo y 14 de Junio de 1848 y 7 de Noviembre de 1849, los frecuentes apresamientos de buques en la cala de Botoya y aún en la misma bahía de Melilla, demuestran sobradamente que, como resultado de la política española, Melilla sólo servía como depósito de confinados y como centro de negociaciones para obtener el rescate de los marinos cautivos en sus aguas: que ya a las agresiones rifenias se contestaba con mas frecuencia con humildes parias, que con el plomo y el hierro" (PEZZI, Rafael. Op. Cit. p. 131).

(33) Sitios, más o menos prolongados como los de 1679 (BACAICOA, 1955); 1774-1775 (MIRANDA, 1775); asaltos de los fronterizos; apresamientos de buques; sublevaciones de confinados; deserciones; etc., ofrecen un panorama muy poco alentador para la primera mitad del ochocientos en Melilla. No es de extrañar, en este contexto, que lo primero que haga Ignacio Chacón del Valle al tomar posesión del gobiemo de Melilla (1848-1850), fuera "dirigir a los jefes de las 5 cábilas una amistosa carta, que leida en una gran junta que al efecto celebraron, en la que sin discusión acordaron hostilizar la Plaza..." (MORALES, 1909. p. 191).

No tuvo suerte la misiva de Chacón, y así, por ejemplo, "durante el año de 1850 raro fue el día en que no resonó el estampido del fúsil y del cañón, rara la semana en que no hubo que registrar algún ataque a la Plaza, pero el servicio de confidencias estaba bien montado, nunca faltó a Chacón noticia de los proyectos de los fronterizos y con eso y con su exquisita vigilancia logró siempre escarmentarios" (MORALES, 1909, p. 193-198).

Los confinados representaban oro problema por su pronta disposición a la fuga. Así lo atestiguan las remisiones periodicas del Estado General de Causas y las sumarias instruidas por el Gobiemo Militar y Político de la Plaza de Melilla y remitidas al excmo. Sr. Capitán General de las Posesiones de Africa:

"Establecimiento penal de Melilla.

El capataz de guardia da parte al Sr. Comandante del expresado establecimiento de haber faltado a la lista de tarde el confinado de $1^{\wedge}$ Brigada $n^{\circledR} 33$ Andrés Gómez Girado que se hallaba de aguador y habiendo sabido el que habla ha sido fugado al campo infiel fronterizo; lo pongo en su superior conocimiento de V. para su satisfacción y fines convenientes. Melilla, 25 de Julio de 1848. José Rodríguez". (Archivo Histórico de Melilla. Cronista oficial de la ciudad. "Confinados", 1848 [s.f.])

Cfr. BACAICOA ARNAIZ, Dora (1955). Dalos sobre el asedio de Melilla en 1679. "Tamuda", Sernestre I, Tetuán, p. 107-111; FERNANDEZ DE CASTRO Y PEDRERA, Rafael (1940). El cerco de Melilla de 1687. Muerte del Gobernador D. Francisco Lopez Moreno, "Mauritania", No 153. Tánger, p. 255-257; MIRANDA, Francisco Sebastián de (1775). El sitio de Melilla de 1774 a 1775.... Tánger, 1939; MORALES MENDIGUTIA, Gabriel de (1909). Op. cit.

(34) Cfr. DOMINGUEZ LLOSA, Santiago (1984). Breve Historia de las Islas Chafarinas, "Aldaba: Revista del Centro Asociado a la UNED de Melilla", Melilla, p. 41-49.

(35) "Quiviana": En árabe "Ras-Quebdana". En bereber "Ait Chebdanen".

Isla del Congreso ("Hachramen Quebdana"); Isla de Isabel II ("Guela"); Isla del Rey ("Tesufa" o "Tenefa"); Islas Chafarinas ("Djafaren"): "Yafarin" las denomina Francisco Coello en su mapa, anotado por Pascual Madoz, al que hemos aludido en nuestra introducción.

Cfr. YUS RAMOS, Rafael, CABO HERNANDEZ, Jose Manuel. Op. Cit. p. 325-333.

"Cabo Tres Forcas" (en árabe, Ras-el-Dir).

"Cabo de Agua": en árabe "Rasel Ma", ocupada por España en 1908.

"Cabo de Guardia", en la desembocadura del Río Tremecén (Ued Tafna), frente a las Islas Limacos o Caracoles (I. Raschgun).

(36) "... una comisión de estudiosos franceses que recorría la costa (en 1830) se vio obligada a refugiarse en las Chafarinas con motivo de un fuerte temporal y tuvieron oportunidad de llamar de nuevo la atención a su Gobiemo sobre el valor de ellas como fondeadero. En ese momento la apetencia francesa sobre las islas estaba perfectamente definida y su ocupación por Francia podía ser inminente".

Cfr. GARCIA FIGUERAS, Tomás (1965). Las Islas Chafarinas, "Africa", suplemento extraordinario de julio, "España en el None de Africa", Madrid, p. 41-42. 
(37) En Consejo de Ministros de 26 de junio de 1847 se acordó la instalación de una guamición en Chafarinas. ante la ocupación francesa de Argelia, iniciada en el desembarco de Argel (1830) y en el interés demostra. do por el archipiélago. de las Chafarinas, buen fondeadero de emergencia y de excelente situación estratégica.

Cfr. GARCIA FIGUERAS, Tomás (1965). Op. Cit. p. 42.

La posesión se realizó al grito de: IIslas Chafarinas por su Majestad la Reina de España! Fue un buen regalo de Reyes hecho por el Duque de la Torre a su joven Reina.

Cfr. ARQUES, Enrique (1966). Op. Cit. p. 150.

(38) El bautismo corrió a cargo del cura pártoco de Mclilla, Bartolomé Fuentes, realizándose las salvas correspondientes.

Idem.

(39) Vicente Darduya desempeñó el cargo hasta el 18 de marzo de 1848, siendo sucedido en el mando por el coronel Juan Irigoyen. Véase lista de Comandantes y Gobernadores Militares de las Islas en: ARQUES, Enrique (1966). Op. Cit. p. 263-265.

(40) Pese a la importancia que Pascual Madoz reconoce a las Islas Chafarinas, estas tras su ocupación caycron en el olvido. Solamente la ocupación del Archipiélago de las Carolinas por Alemania (1899-1919), provoca la reactivación de la Fortificación del Archipiélago.

Cfr. DOMINGUEZ LLOSA, Santiago (1985). Op. Cit. p. 45.

"Mozarquivir": "Mazalquivir" ("Mers-el-Kébir": el gran puerto), en el actual golfo de Orán. Fue posesión espariola desde 1505 a 1792.

"Dejemma el Ghazuat": "Ghazaonet", en la provincia de Tremecén.

Cfr. MAIROT, Capitaine (1915). La fortification nor-africaine, "Les Archives Berbères", Vol, I, p. 161199.

(41) Punta del "Gomerano", alude a la región y tribu de "Gomara", de cuya deformación da "Gomera"; Punta de la "Baba", o Punta del Padre, traducción literal del lenguaje rifeño bereber.

(42) "Fredo", 6, "Freo", canal estrecho entre dos islas, o entre una isla y tierra firme.

El riachuelo es designado por Francisco Coello en su Mapa (1850) como "Arroyo del Gomera", actual río "Bades" o "Badis", término que da nombre a la ciudad que Madoz denomina "Vélez de la Gomera", y que fue, desde fines del siglo XV, activo centro de piratería.

Cfr. El PEÑON de Vélez de la Gomera (1965), "Africa", Madrid, p. 51-52.

(43) Para la historia del Peñón de Vélez de la Gomera: MORALES Y MENDIGUTIA, Gabriel de (1920) Op. Cit., p. 323-397; ARQUES, Enrique (1966), Op. Cit., p. 89-108; PEZZ, Rafael (1893), Op. Cit, p. 12-72, y, 215-234; CARCAÑo MAS, Francisco (s.a.). Las Plazas menores de Africa: Peñón de Vélez, Alhucemas y Chafarinas, Melilla, p. 3-4, y, p. 11-51.

(44) Al igual que hemos visto en las otras Plazas, las dificultades de todo tipo atravesaron las diversas etapas de la historia de Vélez. Hoy nos puede parecer anecdótioo que en 1826, algunos días no pudiera decirse misa "por falta de vino", o que hubiera que comer frío "por falta de leña". Menos aneodótico es que en 1829 soldados y presos tuvieran que "comer perros y ratas por falta de viveres" y que hubiera que exponerse a morir por lograr algunos alimentos. Así, "el 2 de agosto de 1851, Francisco Peláez fue al farallón de Poniente (islote alto de difficil acceso, unos 20 metros retirado de la costa y próximo a la punta del Cebollero) a coger higos chumbos. Desde la costa le hicieron los moros dos disparos y lo hirieron muriendo aquel mismo día".

Además, se sumaban otras dificultades, temporales; naufragios; y las consecuentes incomunicación y falta de abastecimientos; terremotos, como el del 8 de julio de 1848 "que amuinó el homo de pan cocer y parte de la comunicación entre el mismo y el almacón de víveres e hizo avanzar aquel mas de 10 metros en dirección del segundo"; epidemias, etc.

Cfr. MORALES Y MENDIGUTIA, Gabriel de (1920), Op. Cit. passim.

Los médicos se quejaban igualmente de las condiciones sanitarias de la Plaza. El 10 de junio de 1833 "el médico del Peñón exponía al Gobemador los perjuicios que ocasionaba el gran número de perros que había en la PLaza, pues casi todos los barcos dejaban uno o dos". (MORALES, 1920, p. 356).

Los confinados llevaban la peor parte de esta situación, y las fugas no se hacían esperar, utilizando todos los medios a su alcance y siendo, en muchas ocasiones, devueltos al Peñón por las olas.

Las epidemias hacían pasto en la Plaza: la peste bubónica de 1743-174; la fiebre amarilla de 1801; el escorbuto entre los confinados que llevaban dos meses a ración de habichuelas solamente (MORALES, 
1920, p. 366); el cólera en 1833, etc.

De la epidemia de 1743-1744 contamos con un libro que describe pormenorizadamente la situación: "El contagio de el Peñón, que acredita los famosas tropheos de la Facultad Médica. Individual descripción de la constitución pestilente que padeció aquella plaza en el año de 1743". Está escrito por tres médicos: Thomás Exarch, que fue médico de los tres presidios menores de Africa: Joseph Serrano cinujano de la ciudad de Málaga y Juan de Figueroa, que fue médico del presidio del Pcî́n.

Los tres médicos fueron enviados al Peñón "de la orden de su Magestad a la curación del expresado contagio".

Cfr. EXARCH. Thomas, FIGUEROA, Juan de, SERRANO, Joseph (1743). El contagio de el Peñón..., Málaga (Biblioteca Pública Municipal de Melilla, Signat': 094/EXA-Antigüos).

(45) La Isla de Alhucemas, se halla enclavada en el punto central de la costa rifeña, en las proximidades de la actual Al-Iloceima (Villa Sanjurjo), y cercana también a Ajdir, patria chica de Abd-el-Krim.

Tradicional región de insumisión al Sultán, y centro activo de piratería en el diecinueve, poblada por los Bocoya y Beni-Umiagel, se considera algo asi como el Rif dentro de el Rif. El islote de Alhucemas (Hajrat Nokour) configuraba para los españoles una mas de sus diminutas ocupaciones situadas en las escasas aperturas al Mediterráneo de la montañosa región rifeña.

Cfr. AYACHE, Germain (1983). Op. Cit., p. 199-201.

(46) La situación que atravesó el presidio de Alhucemas, en el siglo XIX, no fue mejor que la de las otras Plazas. La falta de viveres era a veces acuciante:

El 17 de diciembre de 1840, el intérprete interino Antonio Antillaque Vidal, Antonio Alvarez Leompart, Antonio Sieva, Jasé Coloma y Bernardo Jose, lodos estos marineros del falucho = Concepción $=$, saltaron a tierra para comprar reses a los moros, quienes los robaron, malaron y quemaron el cadáver de Antilla. que (MORALES, 1920, p. 410).

Las condiciones sanitarias, pese al buen clima de la Plaza, que dice Madoz, no eran demasiado buenas. Alhucemas también vio en distintas épocas cebarse en ella fiebres y epidemias. Así, nada mas iniciarse el siglo, sufrió una terrible mortandad, debido al 'vómito negro', que ocasionó 141 víctimass, mas del tercio de la población (MORALES, 1920, p. 440).

(47) Para una aproximación a la historia de Alhucemas, Cfr.: ARQUES, Enrique (1965). Alhucemas, "Africa". ARQUES, Enrique (1965). Op. Cit., p. 43-49; ARQUES, Enrique (1966). Op. Cit., p. 109-146, y. 260-261; CARCAÑ̃ MAS, Francisco. Op. Cit., p. 5-7, y, 54-73; PEZZI, Rafael. Op. Cit., p. 79-98; MIR BERLANGA, Francisco (1983). Floresta de pequerias historias, Melilla, p. 132-135. 